HISTORY OF THE APPLICATIONS AND DEVELOPMENT SECTION OF THE HYDROLOGIC INSTRUMENTATION FACILITY, STENNIS SPACE CENTER, MISSISSIPPI

By Samuel E. Rickly

U.S. GEOLOGICAL SURVEY

Open-File Report $90-380$

Stennis Space Center, Mississippi 1991 
U.S. DEPARTMENT OF THE INTERIOR

MANUEL LUJAN, JR., Secretary

U.S. GEOLOGICAL SURVEY

Dallas L. Peck, Director

For additional information, write to:

Chief

Hydrologic Instrumentation Facility U.S. Geological Survey

Building 2101

Stennis Space Center, MS 39529
Copies of this report can be purchased from:

U.S. Geological Survey Books and Open-File Reports Section Federal Center, Building 810 Box 25425

Denver, Colorado 80225 


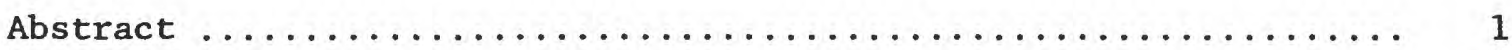

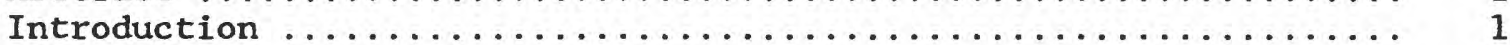

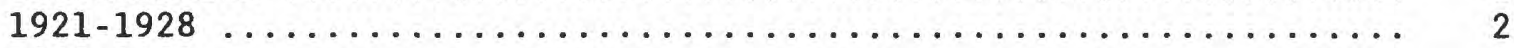

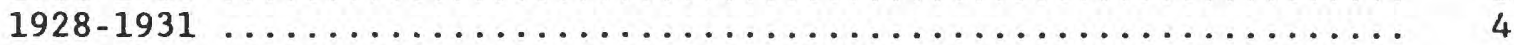

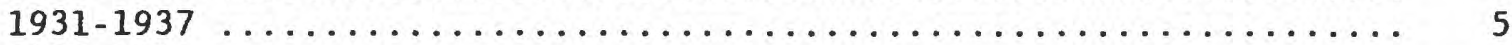

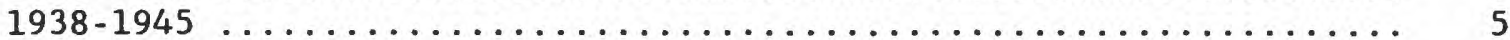

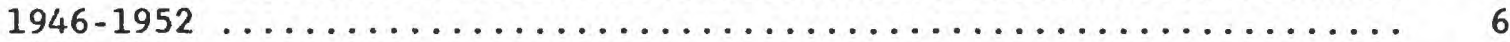

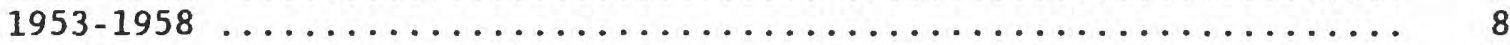

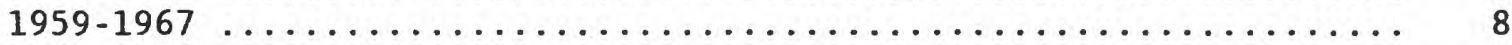

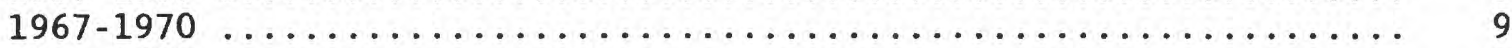

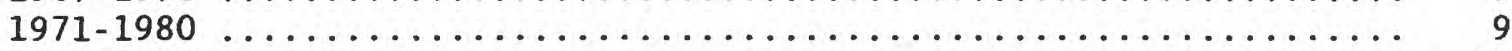

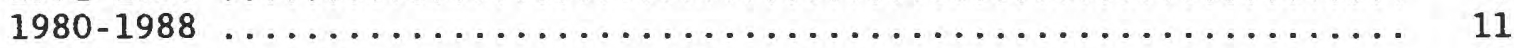

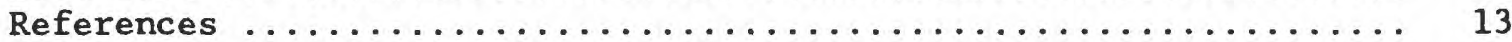

Appendix I. Obituary of Lasley Lee ................... 15

Appendix II. Biography of Carl H. Au ................... 19

Appendix III. Equipment laboratory at Columbus, Ohio ......... 35

Appendix IV. Surface water instrumentation research unit ...... 39

Appendix $V$. Bubbler-gage development ................. 43

Appendix VI. Edgar G. Barron and Harold 0 . Wires, patent

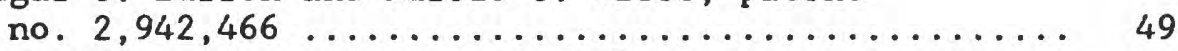

Appendix VII. Formation and continuation of the instrument development laboratory, Columbus, Ohio ........ 63

\section{Illustrations}

Figure 1. Engineering experiment station building, Ohio State

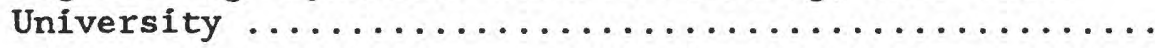

2. Present location of Applications and Development Section, Hydrologic Instrumentation Facility, Stennis

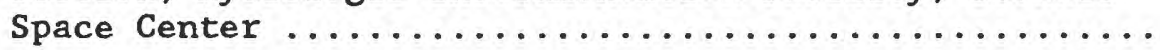




\section{CONVERSION FACTORS}

The inch-pound units used in this report may be converted to metric (International System) units by the following factors.

\section{Multiply inch-pound unit}

foot $(f t)$

foot per second ( $\mathrm{ft} / \mathrm{s})$

inch (in.)

pound (lb)
By
0.3048
0.3048
25.40
0.4536

To obtain metric unit

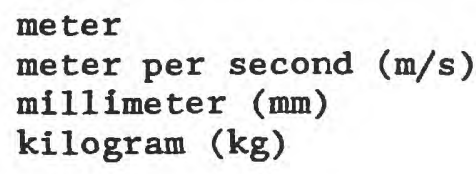

\section{Additional Abbreviations and Symbols}

ADS Applications and Development Section

EDL Equipment Development Laboratory

GCHC Gulf Coast Hydroscience Center

HIF Hydrologic Instrumentation Facility

IDL Instrument Development Laboratory

OSU Ohio State University

WAE While Actually Employed 


\title{
HISTORY OF THE APPLICATIONS AND DEVELOPMENT SECTION OF THE HYDROLOGIC INSTRUMENTATION FACILITY, STENNIS SPACE CENTER, MISSISSIPPI
}

\author{
By Samuel E. Rickly
}

\begin{abstract}
The history of instrument-development activity in the Water Resources Division suggests that often the advances have come sporadically through the hands of diverse independent workers at widely scattered locations. A notable exception to this, however, has been the long period of focussed effort that began in 1921 at the Ohio District office in Columbus. This effort has continued to the present, although since 1971 it has been quartered at the Stennis Space Center, near Bay St. Louis, Mississippi.

In chronological sequence the key individuals who bore much of the work responsibility over the years 1921 to 1988 are Lasley Lee, Car1 H. Au, C. Vernon Youngquist, Arthur Frazier, Keith Essex, Edgar Barron, Harold Wires, Francis Koopman and Vito Latkovich. Attention was directed in the beginning years exclusively to the development of stream-gaging instruments and equipment. Shortly after the end of World War II, however, when new organizational objectives could be set, attention was broadened to encompass equipment development for the ground-water and quality-of-water disciplines as we11.

Over the indicated 67-year timespan, the 1ist of instrument and equipment developments is impressive. A few highlights would include Price current meter improvements, sounding reels and weights, cranes or booms, cable cars, wire-weight gages, electric-tape gages, bubbler gages (mercury manometers), dam instrumentation, and satellite data-relay platforms and receive sites. Past accomplishments are but a prologue for the new chapters to be written under the auspices of the Applications and Development Section of the Hydrologic Instrumentation Facility.
\end{abstract}

\section{INTRODUCTION}

Between the years 1921 and 1988, major decisions were made which led to the establishment of the Instrument Development Laboratory (IDL)--now known as the Applications and Development Section (ADS) at the Hydrologic Instrumentation Facility (HIF), Stennis Space Center, near Bay St. Louis, Mississippi. Several people in that era not only pioneered water-resources investigational techniques but also invented some of the Survey's most valuable water-measuring devices that are still in use. This report describes the principal steps taken in this segment of instrumentdevelopment history and some of the people responsible for them.

The present-day Applications and Development Section traces its roots back to the Ohio District office at Columbus in the $1920^{\prime} \mathrm{s}$, when hydrography was a little-known and imperfectly understood science and the art of stream gaging was in its infancy. The purpose of this report is to describe chronologically the establishment and organizational transition of the U.S. Geological Survey's instrumentation development--from 1921 in the Ohio 
District office to the Applications and Development Section of today (1990). The report highlights principal employees through the years, citing significant accomplishments of those employees in developing key instrumentation for assessing the Nation's water resources.

$$
1921-1928
$$

In 1921, the Ohio State legislature authorized the beginning of a cooperative program with the U.S. Geological Survey to investigate the waters of the State. Funds were appropriated for the biennium beginning in the 1922 fiscal year, and, accordingly, the Survey established the Ohio District office at Columbus (fig. 1), midway in 1921, with Lasley Lee as District Engineer. During his tenure, Lee was a driving force in the continuing development of the Survey's early stream-gaging equipment. He focussed considerable District-personnel effort on developing and revising plans for gaging-station structures, and by about 1928 the stage was set for the great part the Ohio District would have in developing and producing stream-gaging equipment. Lee's untimely death on November 15, 1937, was 1,2 noted in an obituary in the November 10,1937 , Water Resources Bulletin, 1,2 from which the following excerpts are especially significant:

One of Mr. Lee's greater fields of activity and usefulness to the Geological Survey was in connection with the improvement and standardization of structures and equipment for river-measurement work, and he was the author or co-author of a number of pamphlets dealing with that subject. These pamphlets, arranged under the general title of "Equipment for river measurements," are recognized as authoritative sources of information.

As a member of the committee of the Geological Survey for experimental work at the National Hydraulic Laboratory, Mr. Lee was active in the arrangement and supervision of the various laboratory projects relating to measurement of river discharge that have been set up by the Survey for investigations at the Laboratory. These projects included "Studies of artificial controls," "Investigations of current-meter performance in measurements of the velocity of water in shallow depths," "Calibration of a portable Parshall flume," "Study of intakes for gage we11s," and "Measurements of discharge near bridge piers."

1 See Appendix I.

2 Editor's Note: Water Resources Bulletins are dated the 10th of each month regardless of publication date. 


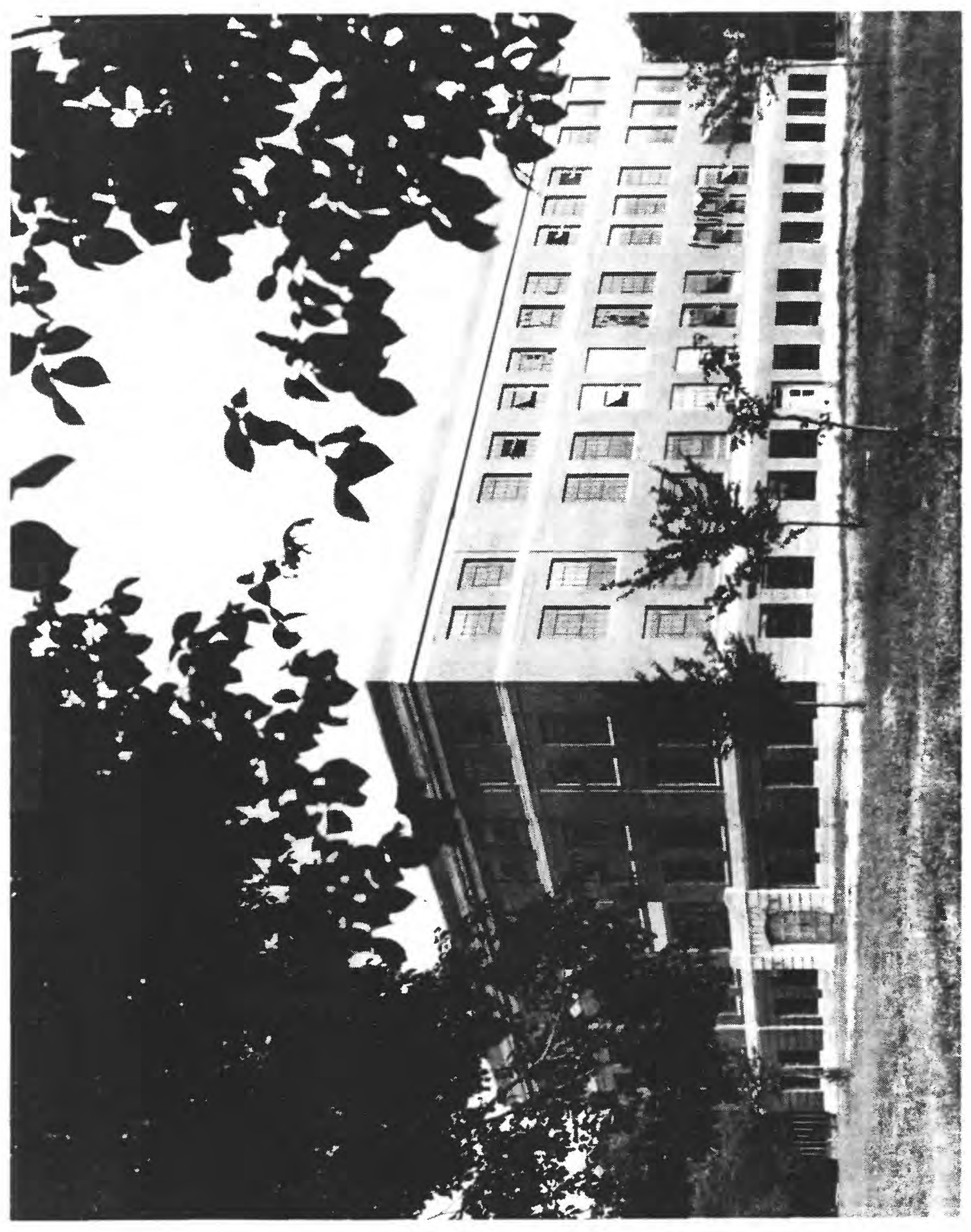

-

एᄂ)

- $7-1$

प्रण

(1) 10

$>$ E

-

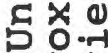

44

(1) 0

+

$+-6$

(s)

$0 \neq 4$

- 0 a

대어

$0 \cdot-1$

-

대되

- $N$

ช $-\mathrm{C}$

다대 थ

न $\cdots$ in

๓

을

ठับ ญ

응

त 0 is

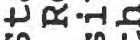

- $4 .-$

$+003$

C $0 ?$

ज्ञ

न्नफ

40 0

से

$x 0$ 으

되-नㄴ 4 U का

\& 10 . -नान्न H口당 0. 0 c.न- EN - 다 0 a क० 나 हु० ज्ञ บ 1 ช 들 4 (1) न्न 늘 ว०० Gu吅 $z$ II 
Since January 1, 1924, Carl H. Au, ${ }^{1}$ had been serving as Senior Engineer in chajge of the Section of Instrument Design, Division of Surface Water, Washington, D.C. In 1928 he was detailed for four months from Washington to Columbus to work with Lee and others on the design of new stream-gaging equipment.

Major items were developed during this four-year period. Usually catalogued with a Lee-Au prefix, they included the following:

Booms (cranes);

Cable car;

Handline reel;

Sounding reels; and

Tagline reel.

It should be noted that aluminum and aluminum alloys became available commercially during this period. Because of their strength and light weight, aluminum alloys were used extensively in the above equipment.

Three Ohio District personnel were involved in the design efforts. They included:

Harold E. Cox, Junior Engineer;

Joseph I. Perry, Assistant Engineer; and

C. Vernon Youngquist, Assistant Engineer.

Faculty members of the Industrial Engineering Department, Ohio State University (OSU), were hired on a WAE (While Actually Employed) basis to fabricate prototypes and produce this new equipment for distribution to other districts. Several of the faculty members who assisted Lee and Au in the design work included the following:

John Denman, Instructor, Pattern Shop;

Jacob Faust, Instructor, Forging and Welding;

Robert Folden, Maintenance Machinist;

Peter Morrison, Instructor, Machine Shop;

Harold Pool, Instructor, Pattern Shop;

Oscar D. Rickly, Mechanical Engineer, Supervisor of Shops; and

R. P. Schnieder, Instructor, Foundry.

1 See Appendix II, "Biography of Car1 H. Au" (1876-1958) by A.H. Frazier, 2 February 1959.

2 Organization terminology changed in later years so that this became the Surface Water "Branch." 
Mr. Au resigned from the Survey in May 1931, leaving as principal participants in the continuing development of new equipment Lasley Lee, Harold E. Cox, and C. Vernon Youngquist. The District office at Columbus was housed on the OSU campus and was given access to the University machine shop, foundry, and testing laboratory. Materials were furnished at cost, and the District office relied heavily on the OSU Department of Industrial Engineering and its personnel for design support, prototype building, and production. Thus, the development needs for heavier equipment came to be satisfied primarily at Columbus; for smaller equipment items the responsibility was assigned to A.H. Frazier who was transferred from St. Paul to the Washington office in January 1935.

The office at Columbus had the added advantage of being not too far from the Washington office, which facilitated any necessary supervisory or liaison-type interactions between the offices. Although actual development work was performed largely by the District personnel at Columbus, the Surface Water Division did establish, in 1931, a committee on field equipment, and the members visited Columbus as required.

Major pieces of equipment were developed at Columbus during this period. They are listed as follows:

Crane trucks; Sounding weights (Columbus type);

Tape gage (electric); and

Wire-weight gage.

As noted earlier, Lee died November 15, 1937.

$1938-1945$

C. Vernon Youngquist became the Ohio District Engineer at Columbus on March 2, 1938. He had a great interest in equipment and persevered in developmental work. In addition to performing the duties required by the Survey's continuing state cooperative program, an aggressive program was launched in cooperation with the Cincinnati office of the Army Corps of Engineers. This new program involved the development of heavy-duty hand and powered sounding reels, cranes, and trucks for the stream-gaging work on larger rivers.

The World War II years brought a marked slow-down in equipmentdevelopment activity. This was due primarily because of personnel and material shortages.

1 Obsolete--otherwise, the basic design is still in use at this writing. 
In September 1945, C. Vernon Youngquist resigned as District Engineer to become Chief of the Ohio Water Resources Board, Water Resources Division, Natural Resources Department, State of Ohio. He was replaced by Tate Dalrymple, who was designated Acting District Engineer.

\section{$1946-1952$}

In September 1946, 0.H. Jeffers replaced Acting District Engineer Tate Dalrymple, as head of the Ohio District, and in 1949, Lawrence (Larry) C. Crawford was appointed District Engineer.

The first equipment laboratory to have its own identity and space was organized and established April 1, 1946, in a two-car garage at the rear of the Legg residence at 144 West Woodruff Avenue in Columbus. This property was adjacent to the Ohio District office, located at the OSU Experiment Station. The staff for the new laboratory included the following:

Harold E. Cox, Mechanical Engineer;

Fred Faust, Welder and assembler (part-time);

Marvin R. Fisher, Instrument Maker; and

Samuel E. Rickly, Mechanical Engineer.

Two reasons strongly influenced this historic organizational step. First, there was the need to increase significantly the rate at which new equipment could be developed, and, second, there was the prospect of dwindling support from the faculty and physical plant of the Industrial Engineering Department at OSU, because of an overwhelming G.I.-Bill student load.

To help set up this new laboratory the OSU Industrial Engineering Department donated surplus machine tools and other equipment. Toward the end of the 1947 fiscal year, the Surface Water Division used the balance of its research funds to purchase shop tools.

In July 1946, it was decided to give added emphasis to equipment development. Arthur H. Frazier, who had been chief of the Division of Field Equipment, Washington office, since July 1941, was moved to Columbus to organize further what was then termed the Water Resources Branch Equipment Laboratory--1ater renamed Equipment Development Laboratory (EDL).

In July 1947, the laboratory was moved from the West Woodruff Avenue garage to 1037 North High Street, where a government-leased building housed four other federal agency offices. The building was an abandoned, automobile dealership (P1ymouth-DeSoto), ${ }^{2}$ and the laboratory occupied what had been the showroom area.

1 See Appendix III, "Equipment Laboratory at Columbus, Ohio," August 10, 1948, Water Resources Bulletin.

2 Use of brand names in this report is for identification purposes only and does not constitute endorsement by the U.S. Geological Survey. 
Following this move the scope of laboratory activity was broadened to include development of equipment for the whole spectrum of water-resources investigations, not just surface-water studies alone. Personnel at this time included the following:

Harold E. Cox, Mechanical Engineer;

Charles Earhart, Engineer;

Katherine 0. Eise1, Clerk-Typist;

Arthur H. Frazier, Mechanical Engineer;

Marvin R. Fisher, Instrument Maker;

Dana Milligan, Watchmaker;

Samuel E. Rickly, Mechanical Engineer;

Terry Shook, Draftsman; and

Delbert N. Townsend, Instrument Maker.

Because of a break in the Public Building Administration lease at 1037 North High Street, new quarters for the EDL were acquired at 1509 Hess Street in October 1949. This building had been occupied by Williams' Leather Products Company, a war-born manufacturer of binocular cases, camera cases, and other defense leather products. After the war, the Company switched to civilian leather products but could not compete and went out of business.

In conjunction with the foregoing move, the EDL acquired a warehouse building at $858 \mathrm{king}$ Avenue, a block away from 1509 Hess Street. The following personnel were added during this time period:

Charles F. Beers, Instrument Maker;

R. Haywood Crouch, Instrument Maker;

Jacob A. Faust, Instrument Maker;

Charles D. King, Instrument Maker;

Dana C. Milligan, Instrument Maker;

Maurice H. Robinson, Instrument Maker;

James C.H. Ryan, Instrument Maker;

Frank B. Watson, Instrument Maker; and

Joseph R. Wilson, Machinist.

In 1952, an addition was made to the building at 1509 Hess Street to house the Ohio District office. About 1948, they had lost their space at the Ohio State University Experiment Station and had been temporarily housed on the OSU campus in World War II barracks.

1 See Appendix IV, "Surface Water Instrumentation Research Unit," Edgar G. Barron, November 10, 1954, Water Resources Bulletin. 
In late 1953 and ear1y 1954, the Instrument Research Unit ${ }^{1}$--1ater renamed Instrument Development Laboratory--was established with Edgar G. Barron as Engineer-in-Charge. Harold (Hal) 0 . Wires became the second member of the IDL staff, and he was the first to fill an Electronics Engineer position in the Geological Survey. This marked formal recognition of the role that the science of electronics could play in Survey instrumentation. During this period the IDL occupied a small room in the front part of the EDL warehouse at $858 \mathrm{King}$ Avenue.

The Bubbler Gage (Manometer) ${ }^{1}$ was developed during the 1953-55 period by Barron and Wires. The government, at this time, was not interested in patent rights on equipment so Barron and Wires applied for and were granted a patent on June $28,1960$.

In ear1y 1956, Arthur Frazier stepped down as Engineer-in-Charge of EDL. He was replaced by Keith $S$. Essex from Surface Water Branch, Denver, Colorado. Mr. Frazier continued work at the EDL developing a vertical vane current meter and writing the history of current-meter development. Also in 1956, George F. Smoot, Engineer, joined the IDL staff.

\section{$1959-1967$}

On July 31, 1959, Arthur H. Frazier retired from the Survey. The following September he moved to Madison, Wisconsin.

In 1ate 1959, EDL was disbanded. All EDL drawings, some personnel (Haywood Crouch, Charles King, Dana Milligan, and Maurice Robinson), and most of the shop equipment were transferred to the Field Maintenance Shop at Silver Spring, Maryland. Keith Essex returned to the Surface Water Branch at Denver, Colorado.

The Instrument Development Laboratory then moved from the warehouse location at $858 \mathrm{king}$ Avenue. The space vacated by the EDL at 1509 Hess Street became IDL's new location.

From mid-1963 to mid-1967, the several Branch District offices in each State were being reorganized and consolidated into single Division District offices for those states. This had the very desirable effect of pooling the work forces for the ground-water, water-quality, and surface-water disciplines.

Edgar G. Barron retired from the Survey in December 1964. Hal Wires replaced Barron as Engineer-in-Charge of IDL.

1 See Appendix V, "Bubbler-Gage Development," E.G. Barron and H.O. Wires,

2 November 10, 1955, Water Resources Bulletin.

See Appendix VI, "E.G. Barron and H.0. Wires, Patent No. 2,942,466." 
Besides Barron and Wires, there were other employees of IDL during part or all of this period. Their names included the following:

Donald I. Cahal, Physicist;

Harold E. Cox, Mechanical Engineer;

Thomas W. Kollar, Engineering Technician;

Jerry E. Mayles, Physical Science Aid;

Duane M. Preble, Civil Engineer;

Samuel E. Rickly, Mechanical Engineer; and

George F. Smoot, Engineer.

$1967-1970$

In Ohio the previously mentioned countrywide reorganization meant combining into one new office the three District offices for the Ground Water, Quality of Water, and Surface Water Branches. This alone would have required more space than was available at 1509 Hess Street, but the decision was made to include IDL and a new regional chemical 1aboratory as well. An abandoned automotive-engine-repair-shop building at 975 West Third Avenue was eventually selected to house the new Division District office for Ohio. After extensive renovations and construction of an addition, the building was occupied in July of 1967 and the IDL vacated the Hess Street facility.

Harold E. Cox retired in November 1968 after 40 years service. Ray Lafferty (Electronics technician) transferred to the IDL from Phoenix, Arizona, in August 1969.

\section{$1971-1980$}

In July of 1971, the Instrument Development Laboratory was moved from Columbus, Ohio, to the Gulf Coast Hydroscience Center, Mississippi Test Facility, Bay St. Louis, Mississippi (fig. 2). In the wake of this move, the laboratory was expanded both in scope of instrumentation development and in personnel.

Hal Wires continued as Chief of this revitalized laboratory until his death on December 28, 1975. In his written communication of 1975 (see Appendix VII), Wires gives personnel lists and some of the principal equipment items under development during much of this period.

Francis C. Koopman, who transferred in January 1976 from Albuquerque, New Mexico, became Chief of IDL in March 1976, and upon his retirement in February 1980, was succeeded by Vito J. Latkovich, who transferred from St. Paul, Minnesota.

1 See Appendix VII, "Formation and continuation of the Instrument Development Laboratory, Columbus, Ohio," H.O. Wires, written commun., 1975. 


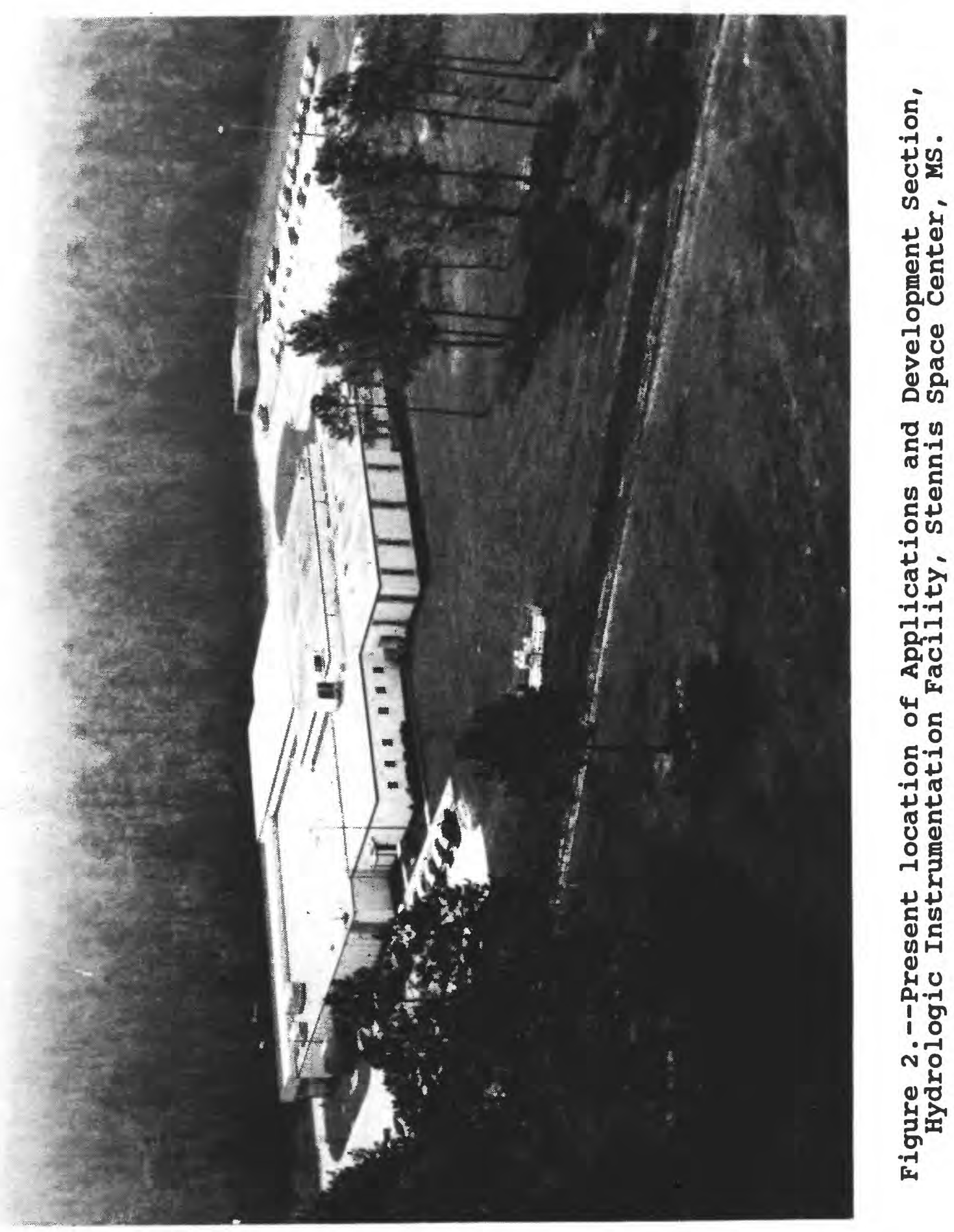


In 1980, the Hydrologic Instrumentation Facility (HIF) was established. The IDL, retaining its title, became a part of that larger organization.

The decade of the 1980's can aptly be described as a high-tech era of data-collection instrumentation development. Electronic techniques replaced many functions, for years, performed by mechanical methods.

Major accomplishments during this time period include the following:

- Minimonitor water-quality monitoring system for temperature, specific conductivity, $\mathrm{pH}$, and dissolved oxygen.

- Instrumentation for measuring and recording streamflow data at 3 river-control structures.

- Downhole data loggers, sensors, and water samplers.

- Improved water-velocity sensors and recording devices.

- Servo controls for manometers.

- Pressure sensor system-replacement for manometers.

- Electronic timers for digital punch-tape recorders.

- Adoption of pressure transducers for water-level measurements.

- Electronic data loggers with a standard sensor interface.

- Specialized water-quality samplers for pesticides and other organics.

o Ground-water flow chambers for water-quality measurements.

- Time totalizers and pipe flowmeter for water-use studies.

- Specialized measurement instrumentation for Federal highway runoff studies.

Key staff members of the IDL for all or part of this eight-year time period included several people. Their names included the following:

Richard H. Billings, Hydrologist;

Edwin H. Cordes, Hydrologist;

James H. Ficken, Hydrologist;

James C. Futre11, Engineering Technician;

Dorothy E. Greenwood, Secretary;

Jack H. Hardee, Hydrologic Technician;

Frank S. Henry, Mechanical Engineer;

James C. Jelinski, Mechanical Engineer;

Roy A. Johnson, Electronics Engineer;

George A. Karavitis, Computer Specialist; 
Francis C. Koopman, Hydrologist;

Ray Lafferty, Electronics Technician;

Russell Lloyd, Engineering Technician;

Vito J. Latkovich, Chief, Supervisory Hydrologist/Engineer;

Henry A. Moore, Electronics Technician;

Wayne Pourciau, Electronics Engineer;

William H. Rapp, Electronics Technician;

Samuel E. Rickly, Mechanical Engineer;

Wayne Rodman, Engineering Technician and Quality Assurance Specialist;

James I. Rorabaugh, Electronics Engineer;

Carl T. Scott, Engineering Technician;

Kirk V. Sharp, Electronics Engineer; and

Alex M. Sturrock, Hydrologist.

In December 1987, Vito J. Latkovich, Chief of the Instrument Development Laboratory, became Chief of the Hydrologic Instrumentation Facility, replacing C. Russell Wagner. Latkovich was succeeded as Chief of the Instrument Development Laboratory by Acting Chief Richard H. Billings. In January 1988, the Instrument Development Laboratory was restructured as the Applications and Development Section (ADS).

The restructuring of the Instrument Development Laboratory was a direct result of a 1987 USGS Program Review Committee recommendation. The new Applications and Development Section was assigned three areas of responsibility: (1) to develop and acquire new field instrumentation, (2) to develop and maintain software for controlling the operation of field instrumentation, and (3) to provide technical support and training in the application and use of field instrumentation. Richard H. Billings was officially appointed Chief of the section in February 1990. 


\section{REFERENCES}

Frazier, A.H., 1959, Biography of Carl H. Au (1876-1958), 10 p.

U.S. Geological Survey, 1937, Lasley Lee, in Water-Resources Bulletin: November 10,1937, p. 183-184.

.... 1948, Washington Office Notes, in Water-Resources Bulletin: August 10, 1948, p. 77-78.

1954, Surface water instrumentation research unit, in Water-Resources Bulletin: November 10, 1954, p. 98-99.

.... 1955, Bubbler-gage development, in Water-Resources Bulletin: November 10, 1955, p. 81-85.

United States Patent office, Patent No. 2,942,466, 1960, Motored manometer for indicating and recording fluid level variations by Edgar $G$. Barron and Harold 0 . Wires, $13 \mathrm{p}$. 
Appendix I--Obituary of Lasley Lee

(Water-Resources Bulletin, November 10, 1937) 
The death of Lasley Lee occurred at his home in Columbus, ahio, on the afterzoon of Nonday, November 15, following an illness from influenz 3 and preumonia of less than five days. Only within less than 20 hours of his death did his illness develop dangerous sywptoms. The suddenness of his death care, therefore, as a great shock to his associates and friends in Columious, and to his grief-stricken family.

Iasley Lee came to the Geological Surrey as a junior enfineer on August 20, 1911, and was connected with the work of the water-Resources 3ranch for nore than 26 years. He was born in Carbondale, Pa.. January 2, 1887, the son of Rev. Charles and Nyrtie Virgicia (Lasley) Lee. His technical education was obtained at Lefayette College ( 2 years), and at the Massachusetts Institute of Technology where he received the degree of Bachelor of Sclence in 1910. पू was elected a membur of the Ohlo State Chapter of Siema Xi in 1924.

ir. Icc Fas croploycd as assistant onfineer in the Slour City. Iow3, offico of the Corps of Bngineers, United States 1ry, In 1910 and 1911, and resizned that position to accept appointment in the Goological Survey. His first assignent in the Survey was in the California district where he remained unt1l June 30, 1916. Durins the last two years of his ewoloyment in California he was conrected with the Investigation of the Hctch Hetchy Valley as a source of additional Fater swpply for the city and county of San Francisco. Following his California assignment he was transferred to the Fashington, D. C. office of the Survey where he remained unt1l January 1, 1917: He was then assigned to the Nashington district ilth headquarters at Tacoma.

In July 1921 a program of systematic stream gaging was begun in Ohio in cooperation with the Ohio Cooperative Topographic Survoy, and a district office was estatlished at Columbus, with Lasley Lee as district engineer. At that time very little strean-gaging work was being done in that state, and the only river-neasurement stations were two stations maintained iy the Geolosical Survey in cooperation with the United States Neather Bureau. At the end of yr. Lee's first year in Oh10 a total of 42 gaging stations were being aaintained and at the end of his second year the number of stations had increased to 46. The rork in Ohlo continued to expand with increase in the demand for stream-filow deta, and for sevoral years 100 or more gaging stations wero in operation, some of ther having been installed in connection with special studies that were not of a continuous nature. At the time of his death, 50 Eaging stations were being maintalnod on rivers in Chlo under Mr. Iee's supervision. He wes co-author of about 30 water-supply papers containing records of strean flow in OhI0; also co-author of \#ater-suoply Paper 486, "7ater powers of tho Cascade RanEe, Part IV, Tenatchee and Intiat Basins"; and Fater-Supply 
Paper 492, "Sumary of hydrometric data in Fashington, 1878-1919".

One of Wr. Leo's greater fields of activity and usofulness to the Geological Survey was in connection with tho inorovenent and standardization of structures and equipment for river-meesurenent rork, and he was the autror or co-author of a number of pamblets dealing with that subject. These pamplets, arranged under the genaral title of "Equipment for river seasurenents", are recosnlzed as authoritative sources of information.

As a member of the comittee of the Geological Survey. far experimental Fork at the Natioual Bydraulic Iaboratory, Ne. Lee was active in the arrangesent and supervision of the various laboratory projects rclating to neasurement of river discharge that have been set up by the survey for investieations at the Laboratory. These projects include "Studies of artificial controls", "Investigations of currentmeter nerformance in measurements of the velocity of Fater in shallow depths $n_{0}$ " "Calibration of a portable pershell ilume", "Study of intakes for gage wélle", and "Keasurements of discharge near bridge piers".

Vr. Iee was a member of the Delta Tau Delta, Sigma $X I$ and Masonic fraternities, Scioto Consistory 320, and Alladin Tewple, A.A.O.N. M.S. He was a nember of the American Society of Civil Ingineers (a past president of the Central Ohio Section), the American Geophysical Union, the Faculty Club of Ohio State University, and President of the Columbus M.I.T. Alumi Assoclation.

On July 11, 1921 he married Viss Mabel V. Arthus of Seattle, Hash., Fho, with one albe-year old son, David, survives him.

Lr. Lee $7 a s$ a descendent of ploneer ancestors, his Ereat havine settled a short distance from Columbus on land fiven him by the Goverment for service in the Tar of 1812. His Ereat-Erandfather donated part of his land for the site of Central College. Mr. Lee displayed all the rufEEd virtues of his ploneer ancestry.

Lasley Lee was a bydraulic engineer of great experience and ability in the highly specialized work of his profession, an untiring worker, a staunch and loyal friend, and a gentleman. H1s death is a great loss to his friends, to his profession, and to all who hed the privilege of being associated with hin or knoring him. The nemory of his genial disposition, his unfalline courtesy, and his kindly assistance to his co-workers, will almays be cherished by his former associates. 
Appendix II--Biography of Carl H. Au (1876-1958)

By A.H. Frazier, February 1959 


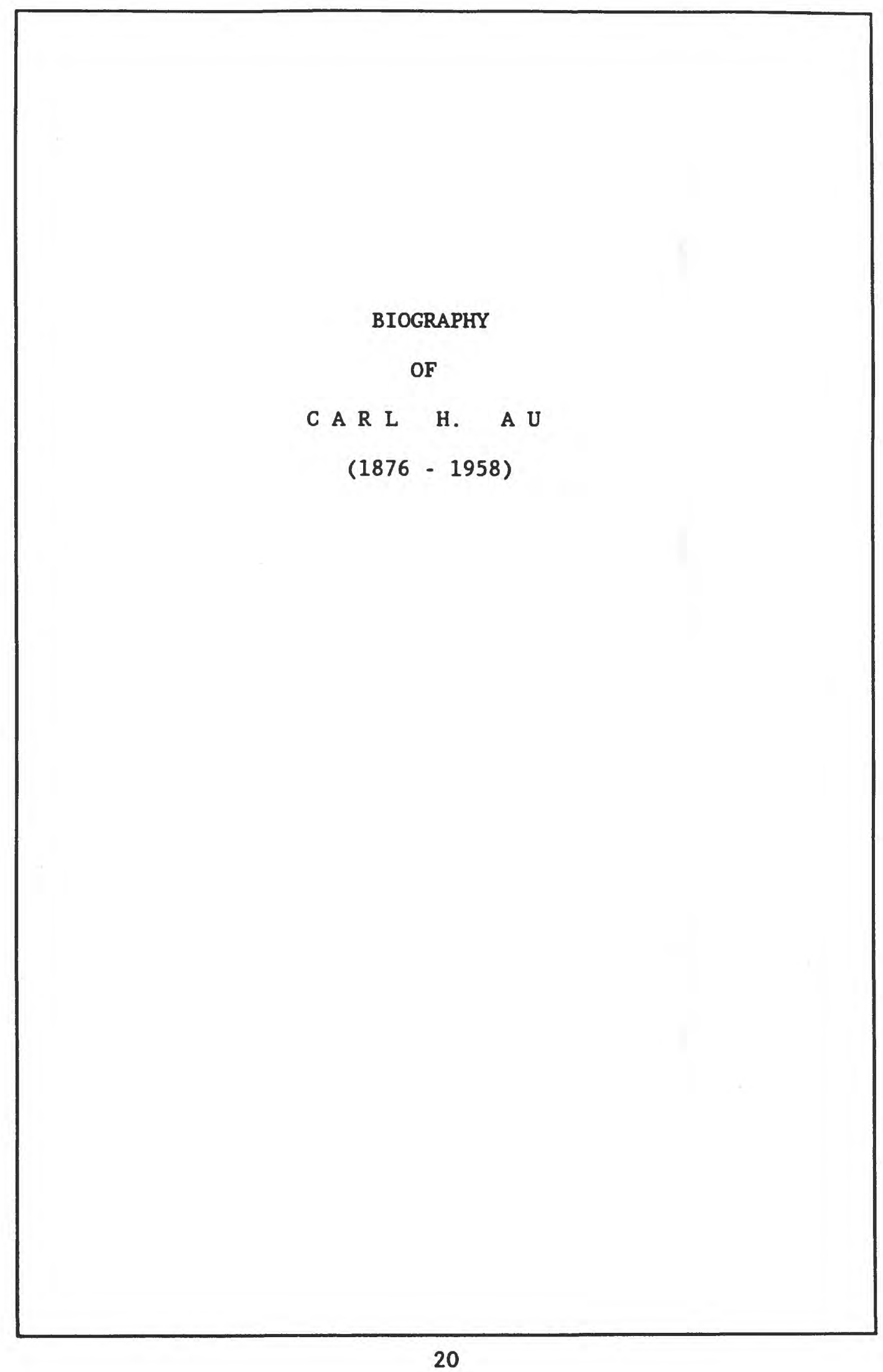




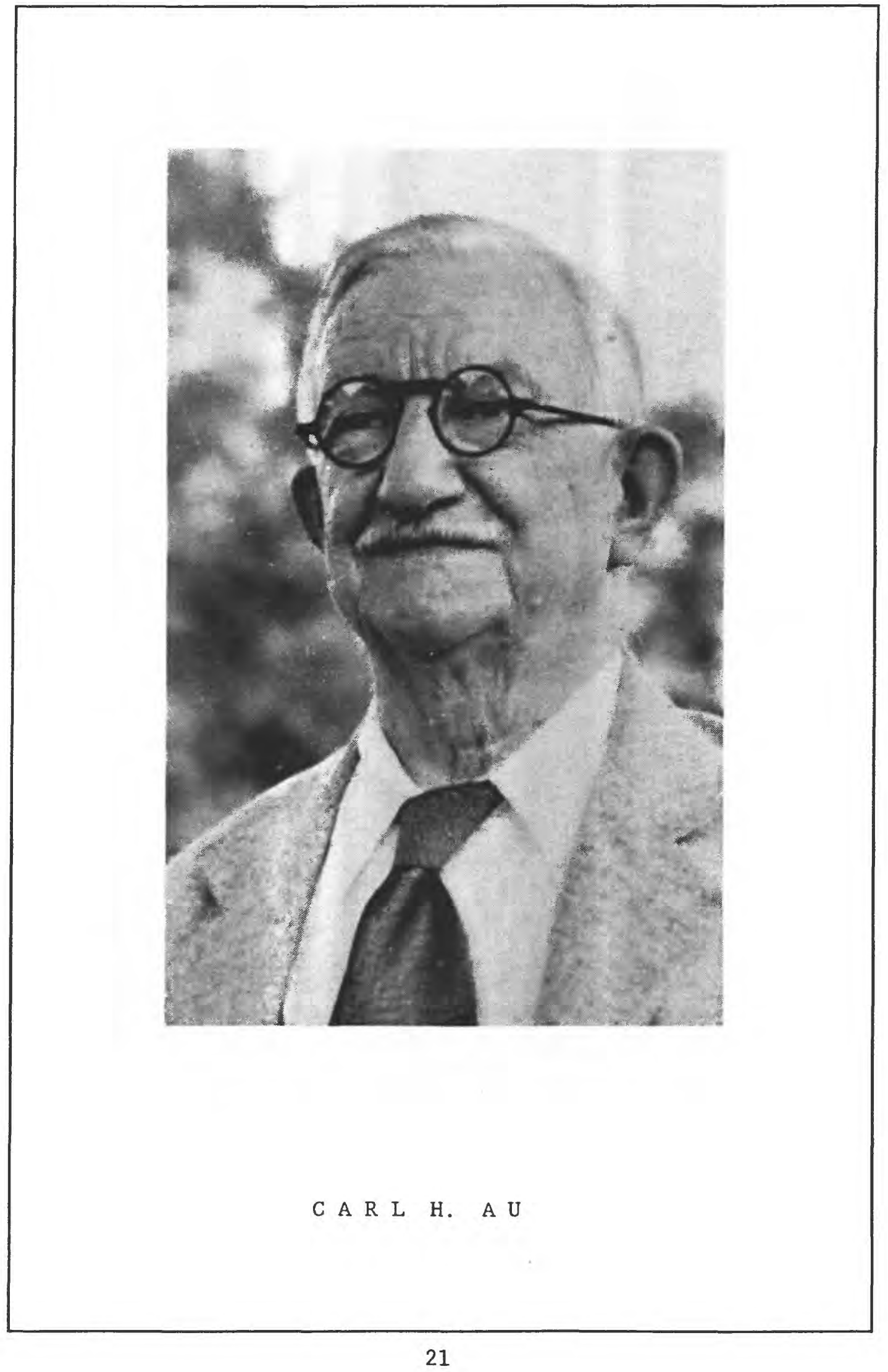


BIOGRAPHY

OF

C A R L H. A U

Carl H. Au, son of Wilhelm Au ( a past member of the United States Marine Band), was born in Washington, D. C. on August 3, 1876. He received his engineering education at the Worcester Polytechnic Institute at which school he was elected a member of the honorary engineering society, Sigma Psi, and was later made a member of the school's faculty. Among the life-long friends he made while at the Worcester Polytechnic Institute was Charles M. Allen, the engineer who developed the Salt-Velocity Method of water measurement.

After having taught at the Worcester Polytechnic Institute for eight years, he returned to Washington where he established an instrument-and-mechanical-engineering shop. One of the instrumentation jobs he undertook while thus employed was that of developing a "Stage-Discharge Integrator" for the United States Geological Survey. E. S. Fuller, an engineer of the Survey, had, in 1913 developed a "Gage-Height Integrator" an instrument by means of which the mean gage height could be derived semi-mechanically from a water-level chart. To make this instrument really practicable for use by field offices of the Geological Survey, it needed a mechanism whereby the dial readings on the instrument could be made to indicate the daily mean discharge of rivers. Fuller and other Survey engineers contributed ideas on how such a change might be accomplished,-. and a crude model was built. That was then turned over to $\mathrm{Mr}$. Au with instructions that 
he build a new working model, ... a job that well suited his talents. In June 1916 the first workable Discharge Integrator was completed. Perhaps the most pertinent statement thereon appeared in the Survey's publication, the "News Letter" of October 23, 1916, wherein the Boston District Office reported as follows:

"The integrator has been tried out in the Boston Office and pronounced a 'great success'. It's not only a time saver, but the most accurate method of determining daily discharges for streams having rapid fluctuations in stages".

Such Discharge Integrators, with surprisingly few changes, are still belng used in all Surface Water Branch field offices of the U. S. Geological Survey. They are well known wherever extensive stream-gaging programs are being conducted.

Officials of the Geological Survey were so well impressed with the work that Mr. Au performed in developing the Discharge Integrator that he was invited in 1916 (the same year that the first workable model was completed) to become a "Senior Engineer" in charge of the development of the Survey's stream-gaging equipment. Here Mr. Au found a fertile field for his inventive genius. He promptly embarked upon a program of development and improvement of equipment that surpassed any similar program in the previous history of the Geological Survey. 
Below is a list (probably not complete) of the patents that were awarded to him. It will be noted that two of the patents in this list ..-the 3-lens "Aero Camera", patented jointly with James W. Bagley, and the "Flexible Power-Transmitting Device", intended primarily for use with that camera, involved work for another activity of the Survey,--presumably the unit that was then called the Alaskan Division. This camera was the forerunner of the TriMetrogon Camera by means of which thousands of square miles of reconnaissance maps were made for American military purposes during World War II.

LIST OF PATENTS AWARDED TO CARL H. AU Patent No. Date of Award Title $1,331,311 \quad 2 / 17 / 1920 \quad$ Flexible-Cable Power Transmitting Device

$1,499,2836 / 24 / 1924$ Water-Level Recorder

$1,599,400 \quad 10 / 27 / 1925$ Aero Camera

$1,604,73210 / 26 / 1926$ Water-level Recorder

$1,626,715 \quad 5 / 3 / 1927 \quad$ Current Meter

1,644,005 10/4/1927 Current Meter

1,704,162 3/5/1929 Current Meter

$1,609,008$ 11/30/1926 Water Level Recorder

1,676,848 7/10/1928 Water Level Recorder

$2,108,037 \quad 2 / 15 / 1938 \quad$ Water Level Recorder 
Julien P. Friez and Sons (an instrument manufacturer located in Baltimore, Maryland) undertook the production of several of the recording gages on which $\mathrm{Mr}$. Au held the patents. Two of the most commonly-known recorders among that group were the "Au Drum Recorder", and the "Model FA Friez Continuous Water Stage Recorder" ( the letters "FA being the initials of the manufacturer, "Friez", and the inventor, "Au").

Prior to 1925, the Small Price Current Meter (which the Geological Survey was then using almost exclusively in its stream gaging operations) was normally furnished with two contact chambers, ..-one of which would produce an electrical contact for each revolution of its bucket-wheel; the other of which would produce an electrical contact for each five revolutions of the basket wheel. This arrangement made it necessary for each field engineer to carry the extra contact chamber with him, and to change from one to the other as the velocity conditions at each gaging station demanded. It also made it necessary for the current meter's rating to be made in two parts,.. the low-velocity portion needed to be made with the one-contact-per-revolution contact chamber, and the high-velocity portion with the penta-contact chamber. To correct this 
annoying circumstance, Mr. Au designed a new contact chamber incorporating both the single and penta features. To shift from the "single" to the "penta" arrangement, the engineer needed only to shift the electrical connection from one to the other of two binding posts he had provided on that new chamber.

In connection with the horizontalshaft current meters on which he had obtained one of the above-1isted patents, he later conceived the "Au Weightless Meter Propeller", the purpose of which was to relieve the bearings of the weight of that propeller when the instrument was submerged in water. This propeller was comprised of a small sealed tube onto which four helical vanes were attached, the buoyance of the sealed tube being such that the specific gravity of the entire rotor assembly was the same as that of water. Another type of a meter, the "Au Deep Well Current Meter" (built in collaboration with Oscar Meinzer and Albert Fiedler of the Ground Water Branch, U. S. Geological Survey) is known throughout the world.

Some of the earliest water samples obtained at Lake Mead (behind the Hoover Dam) were taken with a sediment sampler of his design and construction. 


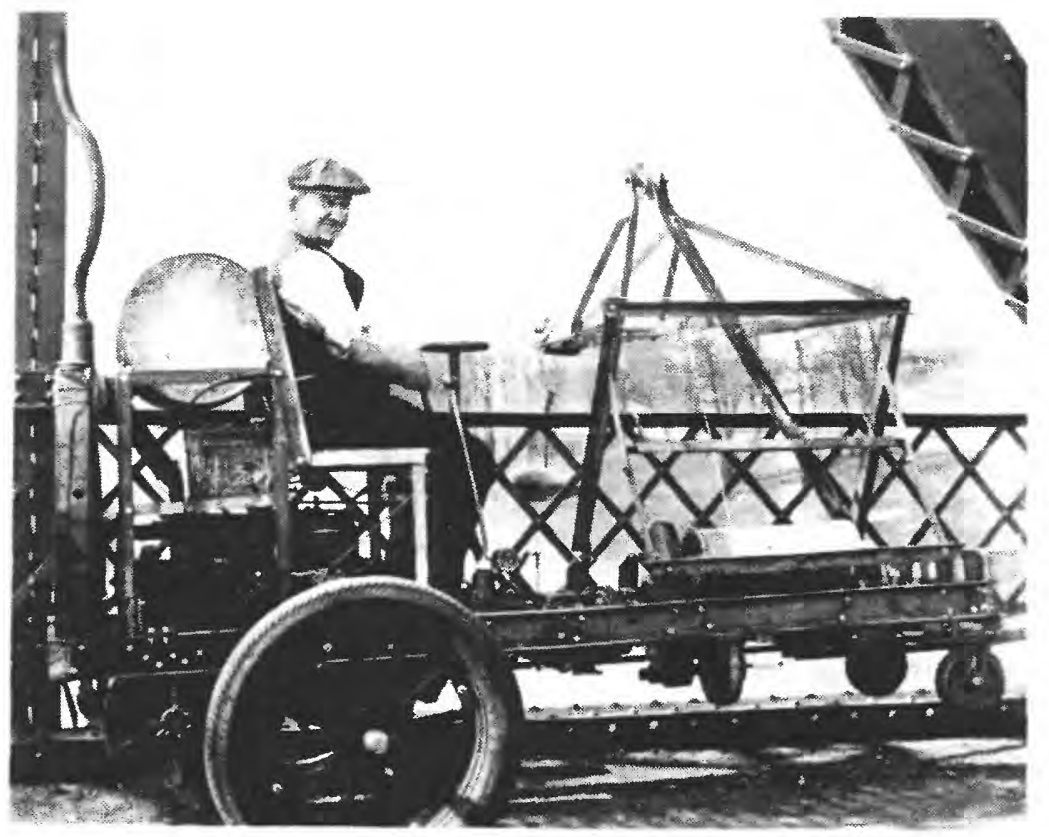

FIRST POWER-OPERATED CRANE

BUILT ESPECIALLY FOR STREAM GAGING

(TO MEASURE THE MISSISSIPPI RIVER AT VICKSBURG) 1930 


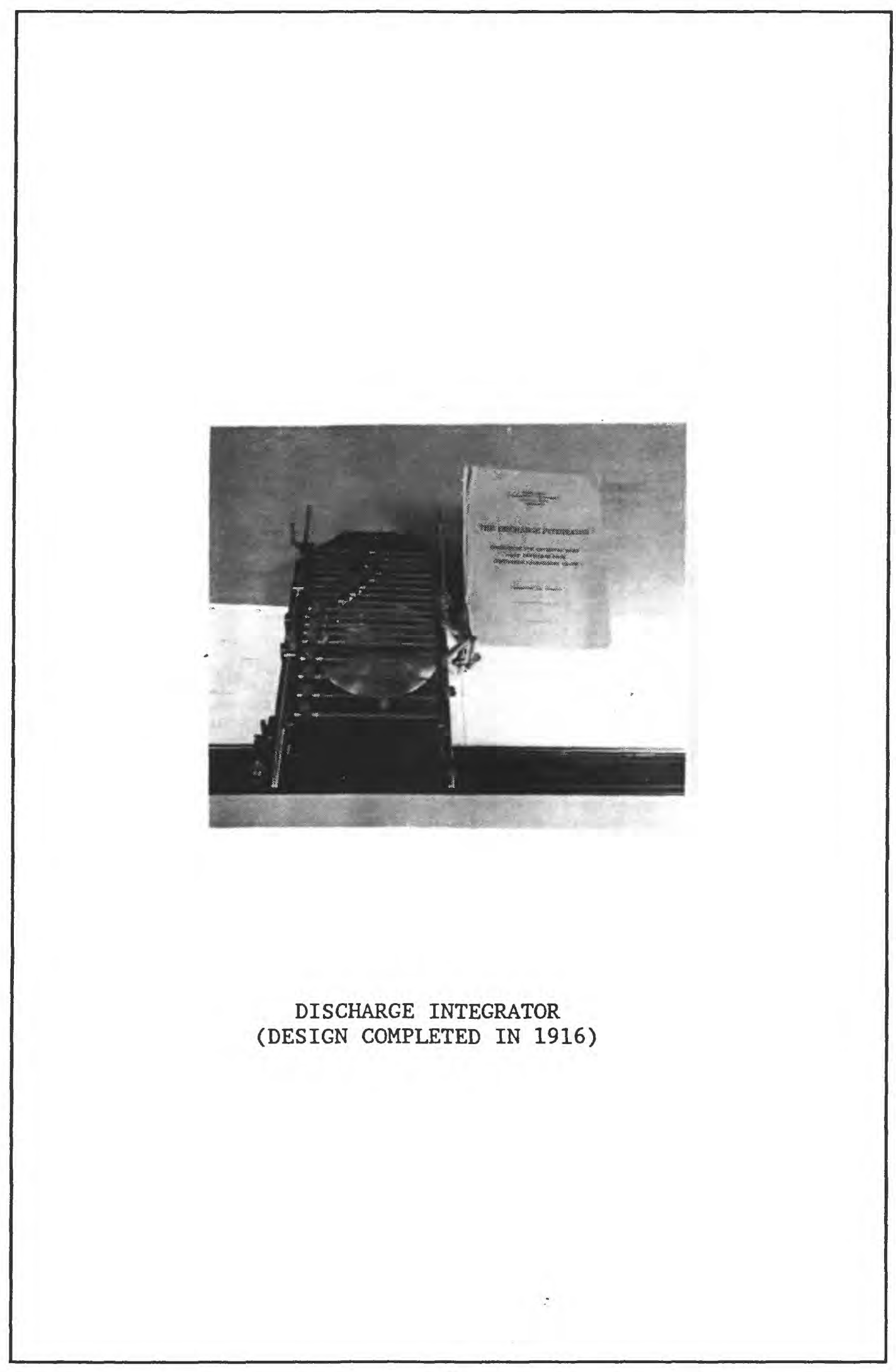


When performing development work in connection with stream-gaging operations, he received much encouragement from John C. Hoyt of Washington, D. C. who was then in charge of the surface-water investigations of the Geological Survey, and Mr. Lasley Lee, the district engineer of the Columbus District Office of the Surface Water Branch of the Survey. Mr. Lee's office was then located on the campus of the Ohio State University, the machine shops of which were then under the supervision of Professor Oscar Rickly.

Prior to 1928 the development work performed by $\mathrm{Mr}$. Au dealt largely with hydrologic instruments, such as current meters and water-level recorders. Relatively scant attention had been given to the associated equipment that was needed by field men for collecting stream-flow data. In recognition of that need, Lasley Lee arranged (during 1928) with the Chief Hydraulic Engineer, Nathan Grover, for Mr. Au to visit the Columbus district for the purpose of acquainting him with the field engineer's problems. That visit was one of many that Mr. Au made to Columbus during the remaining years that he was employed by the Survey. During those visits, Messrs. Lee, $\mathrm{Au}$, and Rickly collaborated in the design and construction of many items of stream gaging equipment, most of which are still being used by the Survey's staff of field engineers. It may be appropriate to mention here that 
during this period (circa 1928), the aluminum industry was just beginning to flourish, and aluminum structural shapes as well as castings had become available commercially at reasonable prices. The lightness, cleanliness, durability, and strength of that new metal appealed to these three collaborators, and they introduced its use in the construction of many of the items which they designed.

No complete list has ever been made of the many devices that were designed by $\mathrm{Mr}$. Au either "on his own" or in collaboration with Messrs. Lee and Rickly, but there follows a list which at least partially represents the items of equipment he had developed.

Lee-Au Sounding Reels ( 4 types)

Lee-Au Boom

Electric Tape Gage (with built-in electric generator)

Improvement of the fore-runner of the Type A

Crane and development of first Crane Truck

Au Spiral Connector

Au Lace Type Connector

Au Wheel Type Connector

Lee-Au Handline Reel

Lee-Au Tagline Reel

Lee-Au Gaging Car

Au Car Puller

Vicksburg Power Crane

Elliptical Sounding Weights

Pendulum Type Crane Protractor

Float-Gage Bracket

Wire Welght Gage 
After leaving the Geological Survey (in 1931) Mr. Au and his son, Carl F. H. $\mathrm{Au}$, re-established his instrument shop in a small building at the rear of his residence at 1009 Independence Ave. S. E. in Washington D.C. , and continued to work leisurely at his favorite activity, instrument making.

During this retirement period, he conceived two interesting inovations in water-level recorders. One of them contemplated the elimination of a pen or pencil stylus for registering the gage-height. This was accomplished by fixing a smalldiameter piano wire in a helically-shaped position onto the drum of the recorder, and arranging a "hammer" (comprised of a flat metal bar) to be supported longitudinally over that drum. The chart paper was drawn by clock-work through the space between the metal bar and the helical wire on the drum which, in turn, was appropriately rotated by the float-wheel and its associated equipment. The "hammer" was hinged to the frame of the recorder, and connected with the clockwork in such a manner that it would tend to be raided a short distance above the paper until, at the end of an appropriate time interval, that bar would be allowed to drop. Its impact at the place where the paper rested between the bar and the helical wire would cause a tiny hole to be punched through the chart paper. That hole registered the correct gage height for that moment. This operation was repeated often enough to create, by means of a succession of holes, a continuous record on the chart, 
of gage heights. The line of holes, although not as clearly visible as an ink line, could be made very visible by blueprinting the chart, - the light in passing freely through the holes would produce a clear trace of the record on the blueprint.

The other development referred to above was comprised of a recording device whereby one could telephone to an unattended recording gage shelter, and would receive a buzzing signal the length of which, if timed with a stop watch, could be translated into a reading of the existing stage of the river at that time. The principle of operation of this device was also incorporated in a "remote" recorder, several of which he manufactured.

Mr. Au was a very welcome visitor wherever he went. He loved children, and the sons and daughters of his intimate associates invariably called him "Uncle Carl". The daughter of one of the Columbus District's clerical employees still recalls as her greatest childhood thrill the occasion when "Uncle Carl" took here into a "lof store" and allowed her to take home all of the things that appealed to her.

$\mathrm{Mr}$. Au was an accomplished composer and musician. In his youth (1890 to 1898) he played the clarinet in the District of Columbia's National Theater Orchestra. The piano and violin were also among his favorite instruments. It has been estimated that he composed over 200 songs in his lifetime, although none of them was ever published. 
Many of his songs were dedicated to people he either enjoyed or admired. One, for example, was dedicated to a favorite movie star. Having especially high principles and a strong sense of propriety, he promptly destroyed that song when on a later occasion he saw that same actress appear on the screen wearing clothing that he felt was too revealing.

His son, when commenting on those characteristics, has written, "Dad was a perfectionist, and expected perfection in those he 1iked. When it was not forthcoming, that person was no longer in his good graces. That's as mild as I can put it".

Mr. Au was a member of the Cosmos Club, and (as stated) a member of Sigma Psi, honorary engineering Society. At the time of his death, November 24, 1958, he left a son, Carl F. H. Au, and an adopted daughter, Mrs. Fran G. Mink, two grandchildren and two great-grandchildren. His wife, the former Bertha Maria Briggs, died in 1945.

As is true with many highly skilled and productive men who have lived many years beyond the peak of their productiveness, time has dimmed the memory of his many fine achlevements, ..--and but few persons were left at the time of his passing who knew of, and recognized the many contributions he made to instrumentation in the fleld of hydrology. 
Written by

A. H. F R A Z I E R

February

1959 
Appendix III--Equipment Laboratory at Columbus, Ohio (Water-Resources Bulletin, August 10, 1948) 


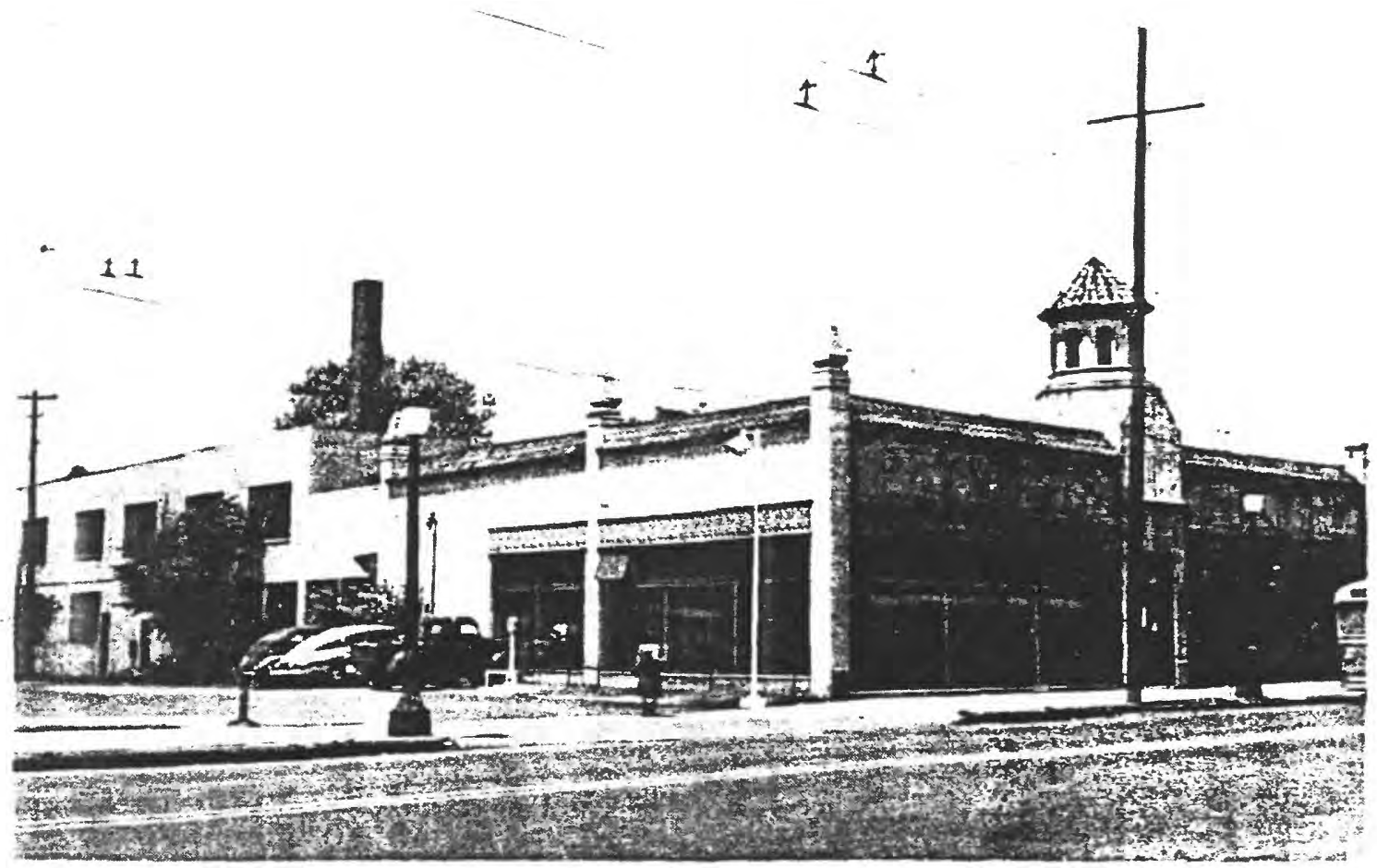

Columbus equipment laboratory (see page 77).

A memorandum for the official use of nembers of the tater Resources 3rsnch, jeological Survey.

By direction of the jecretary of the Interior the matter contained heroin is pressnted as administrative infomition and is reuuirec for the proper transaction of jublic jusiness.

As the contents are highly informative und relate generally to current work, the Bulletin should be made available as promotly as practicable to each member of the tecinnical personnel of the Brazch. The topics should be studied and, as there is opportunity, thoroughly discuszed by all. The views expressed in this 'ulletin are those of the writers ana not nocessarily those of the district offices to which the writers are assigned, or those of the ashington office. 
WASEINGTON OFFICE NOTES

Bautprent iaboratory at columbus, on10

\section{Symopses.}

Tho Water Resouroes Branch Bqulprent Iaboretory has rooently occupled now quarters at 1037 North H1gh Street. Columbus 1 . Oh10. and increesed 1ts personnel and shop feollities. These notes describe briefly the early hiotory of the Inboretory and state the purposes for whl $\mathrm{ch}$ the expansi on was intended.

The 1llustretion on the front page of this 1saue of the Water Resouroes Bullotin shows the bullding the houses our present Bquipment Inboratorg in Columbus. It 1s a largo twostory concrete-block atructure leased by the Public Buildinge Adminlatration. (The second tory 1 a toward the roer of the bu1lding, out of the runge of the camere.) The Columbus activitios of 11 ve other Foderel Agencles are also housed thereln. The 2,560 square foet nearest the camere, In the southeast comer of the bullding, heve been occupled by our Inboretory since August 1,1947 , as indlceted in Water Resources Branch C1rcular dated August 9, 1948, Equi pment--F101d-Equi pment Section. Columbus. A request hes been filed for an additlonal 800 to 1,000 square feet of $1100 \mathrm{r}$ spece on the second floor for englneeringdoal gr, offlce, and clock-ropelr work, but that request has not jot boen granted.

The establi shment of an equipment-development center in Columbus for eervicing the needs of the Surface Weter DIVlalon apparentls had 1to orlgin in 1928 men, in reaponse to a roquest by Dis trict Ingineor Laslor Loe, Nr. Carl Au wa detalled from the Washington office to Columbus for 2 or 3 months for the purpose of developing cable cars, reel. and othor streamonging equi pment (Columbrs, 129 p. 10). Through the cooperation of Mr. Oscer Rickly (then Professor of Industriel snglneoring, Oh10 State OnIverel tJ). Mr. Au obtalned permission to use the mehinery and facliltios of the Univeralty for constructing model of varlous cranes and rools, some of whl ch are st1I Identlflod with his name.

The cooperation ostablishod at that the wh the UnIrerelty was so well-founded that 1 ts shop facliltios and the serrloes of Mr. Rickly and othors of 1t faculty (durlng thols spare time on a WAR basls) have boen used by the Branch for about 18 jears. By that time, the needs of the Branch hed far outgrown the facliltios thet the Unlveralty could reasonably make avilable. On Apr11 1, 1946, therefore. the Lebortory mo moved into rented quarters-a concrete-block bullding having ebout 900 squere reet of floor space loceted at the rear of 144 Wost Woodruff Avenue in Columbus. Wi thin a year the noed for st111 lerger quarters became ovident and the prosent quarters wore Inalis arranged for and occupled as of August $1,1947$.

When the move to the now quarters took plece, the Leborntors wa granted a more Independent status and the scope of 1 ts activities was brondened to include work for all D1v1sions of the Water Resources Branch. Op to that timo, it had boen an "extre currlculer" act1 v1ty of the Columbus District, and 1 ts services were confined largely to activities of the Surface Water DIvislon. Concurrent with the move to the new quartors, the Columbus DIstrlot wa relleved of I ts direot sponsorshlp of the Laboratory owing to the inoreasing burden the Iaboratory had bocome, but the district offlce tili asis ts the Inboretory in en advisom capacity and handles most of the housokeoping runotions. Admin1strativelJ the Inboratory Is Independent to the extent that it is now directly responelblo to the Chlof Bjdraulic Bngineor.

Perhepe the alms and prosent outlook of the Inbortory can beat be described by the followIng oxtruct from a tatewont the t rocently propared as justiflcation for expanding this facill ty:

It 1s proposed to enlarge the present faclilt1es of the Equipment Laboretory at Columbus in order to provide adequa toly for the repldis growing needs for speclellzed oquipment to perform mterresources investightions. In the past, the oquipment unit at Columbus has boen Iargely ongaged in the development of oquipment for surface-weter Investlgetions and, in mang cases, the conotruction of cortain speclelized lands of equipment. The new onlarged unit will bo aclentiflc laboretory rether then an equipment shop in the usual sense, as It w11l bo used for the prim ry purpose of inveatignting and proparing woridng models of highly spociellzed equipment for all divisions of the Weter Resources Branoh.

It 18 expected the much of the present mater-resources equi pment w1Il be modi fled considerubly in order to improve it in appearance, userulness and accuracj. In addition, many 1 tems of now equipent ere noeded badls whil ch wili require. coniderablo clentilc research for 1 ts proper development. The Water Resources Branch is at loast 10 joars bohind in oqul pment development work, as much of the present equipment 1s antiqua tod. There are meng eclentific developments that occurred during the last war porlod whlch probably could bo adapted for use by the Water Resources Branch bJ carenI research and modiflcation to moot our needs. Some of the olectronte developments, In partlculer, doubtlosa would bevo rether vide application and probably would greetis 1mprove the tools which the Water Rosources Branch so badIf neods to perform the worl which has expanded greatly during the last 20 jours. It hes not beon poselblo to do areat deal of research and development work for a number of years beceuse we have not had a sultable laborntory adequately manned wi th personnel who are Intim taly ecqualnted with the neods of the Brnnch and who could dovote all of thelr time to such work.

It $1 \mathrm{~s}$ not intended thet the Columbus Laboretory ahould bo in anj senso a manurecturing unit. The only construction work thet should be done at Columbus would be the construction of worlelng models in those cases where it would not be reasiblo for private Industry to manufacture the flnlshod products for actual use ol ther because of very $11 \mathrm{mlted}$ needs or because 
of the preclaton atandarda that might be requilred. Add1 tional repe1r work on waterresources equipment should doubtless be perforwed in the Iabor tory. Included in such repalrs would be atop watches and recorder clocks. Most fleld offlces heve boen unable to obtain ropalrs commerclally to timepleces within a reasonable length of time. In fact, many offices heve been unablo" to obtain repal rs t all within their dis tricts. Pany jewelers soem to be uninterested in this type or work and give very poor service. In most places the che rgos are extromely high. It $1 \mathrm{~s}$ belloved that repalrs can be made in the oquipment laboratory at about one-half of the averago cost comercially. However. It 1s not contemplated that ropalrs $w 111$ be made on equipront in geners uso such as level s and trunsita thet can bo done in the Survey's Flold Equipment shops.

At the present time Columbus $1 \mathrm{~s}$ particularly woll aultod a location for contInuation and onlargoment of this laboratory unft because of the largo atroams that are within reasonable diatence whore model mes be testod, and because of wher largo ground-vater programs in the area as woll a quallty-or-weter programe that are well auited. for the teating of twal oquipment. In addition, the Colvmbus equipment centor has boen worlding closels w th the Oblo state OnI veral ty for a minber of jears. Menj of the mechanlcel and sclentiflc instructors and prorossors at the Und verelty are well quellfled to asist in partl cular problems concerning moter-rosources oqulpment development because of long acqualntence with and particlpetion in this work. The facliltios of the unf versit have been and will cont1mue to be a vellable for certaln types of work whore special toeting equipment 1s needed. Columbus is also perticularly well situnted wth reference to foundrles and mamufacturing firms that would, in all probebllity, bid on much of the equipment mamectured. Frequent contacts w th these mamufacturers are required in order thet the flnal oquipment w11 be strictly in accordance with apociflcations. Columbus $1 \mathrm{~s}$ elso relatively near to Washington where 11 elson with the Weshington office could be readily mintalned wil ch would be of much advantage for the present a least, a well as reasonably convenlent to flal ting fleld office peraonnel who could stop there enroute to or from Whahington and consult with the fleld equipmont labore tory personnel.

The Corps of Ingdneers, through thelr Loulsv1110 DIstrict, obtain equipment, dovelop equipment and distribute $1 t$ to all of the Army Bnglneer Diatricts throughout the ent1re onited states. It is important from our atandpolnt as woll as that of close coordination between other Federal agencles thet the work of these two agencies be integrated. Reasonably close 11 alson has been malntalned between the Corps of Pagineers and our exlating Columbua laboretory. It 1a our dasire a well as thet of the Corps to rurther this close work. If this leborntory were 10catod any other place than in the Ohio RIver Vailey thi a llalson could not bo closely maintalned, and it is quite possiblo that part of the loadership in the development or water-rosources equipment would be taken over by the Corps of Bnglneors. They have indlcated that is a Survoy laboratory is in tho vicin'ty of the Ohlo RIver DIVIs1on, and particularly near thelr Loulstille off1ce, they would be more than pleased to heve us take over some or all of the development work which they are now dolng on wer-resources equipment. Thls, wo think, is important From the standpolnt of the Survey in the furtherence of the good relationa betwoen those two agenc1es and also to avold compet1tive duplication of work.

\section{Ohfo Basin Reglonal Chomical Laboretory}

During the $1948 \mathrm{flscal}$ jear, funds wore made avilable to the Quellty of Water D1vision for the os tablishment of a reglonal laboratory in the OhIo RIver Basin. That laboratory was established to provlde centrallzed recll1ties for bandling quality of water studios in the lower Ohio fiver Besin. The great industrial expansion in the Oblo R1ver Basin during recent yoars hae roculted in a domand for extromely lergo quantities of meter of eccoptablo quality. Recognlzing the ecute need for rellable inforintion, sevornl of the states in that region have requested the coologlcal surver to undertake Investigations of the chemlcel qual1 ty of thelr witer rescurces.

After a great deal of deley, resulting from an extrome shortago of commercial apace, oustablo quartors wero Ninnly leneed at 2822 Fat Min street, Columbua 9. Oh10. The laboratory surniture is under contract but probably w11 not be dellverod and installed much before January 1, 1949.

The Ohlo Basin reglonal laboratory $1 \mathrm{~s}$ under che Imediete supervision of W. I. Inear, formerly district chomlat in Ralel gh, H. C. Ho is now in Columbua and has taken over responalbil1ty for the current quallty-or-water program in Ohio.

As a temporary arrangement, samplea collected in connection with the Ohlo cooperetive progrem are bolng analyzed in laboretory space mado avellable by the c1 ty of Toledo at thelr ColI1ns Park Filtretion Plent. Merle B. Schroeder has boen asalgoed to the Toledo laborntory during the past joar.

\section{Status of Water-Supplt Papers}

The status of unpublished Weter-supply Pepers 28 of Auguat 1, 1948, 1s given bolow:

\section{Reporta on Surface Water}

Annuel roports, 1945

Part 3. Printer.

5. do.

12. do.

Hame11. do.

Annual roports. 1946

Part 1. Revlewed: 97\%; not recelved: $3 \%$.

2. Copy typed.

3. Cops typed; $98 \%$.

4. Bditor.

5. Rev1 ewod: $97 \%$ not recelved: $3 \%$.

6. Rev1 ewed: 90\%; not recelved: $10 \%$. 
Appendix IV--Surface Water Instrumentation Research Unit By Edgar G. Barron

(Water-Resources Bulletin, November 10, 1954) 


\section{ORGANIZATION AND ADMINISTRATION}

Pacific Coast Center, Menlo Park, Calif.

By T. W. Robinson and C. S. Howard (Staff Representatives, GW and QW. respectively)

The Van Pelt Report suggested the setting up of certain Survey Centers, one of which has been located in Menlo Park, Calif. Menlo Park lies about 30 miles south of San Francisco, on the west side of San Francisco Bay. This location was selected because of its proximity to Leland Stanford University. The University, located in Palo Alto, which joins Menlo Park on the south, is about 2 miles from the Center. The first unit of the Menlo Park center (fig. 1) has been occupied for about 10 months, and most of the people in this unit are employees of the Geologic Division.

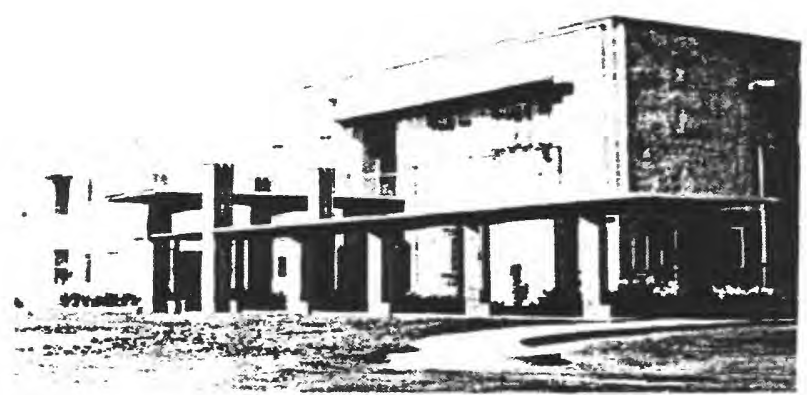

Figure 1.-Geological Survey Pacific Coast Center, Menlo Park, Calif., showing main entrance. Water Resources offices are at the extreme left, second floor. Photograph by $\mathrm{H}$. Veronica Nye.

The Water Resources Division is represented by three employees. T. W. Robinson, staff engineer representing the Ground Water Branch, is working on the hydrology of arid regions particularly on phreatophytes. C. S. Howard is the staff chemist representing the Quality of Water Branch, and the secretarial work for both branches is done by Mrs. Dolores Triano. The total space allocated to the Water Resources Division is about $1,700 \mathrm{sq} f \mathrm{f}$, of which approximately $900 \mathrm{sq} \mathrm{ft}$ is laboratory space. The space includes approximately $150 \mathrm{sq} \mathrm{ft}$ used by the two branches as a drafting room and library. The library consists of technical papers, maps, and publications of particular interest to the work being done in these offices. Many of the publications are not normally found in the libraries of the district offices of the Survey. Of the remaining $650 \mathrm{sq} \mathrm{ft}$, approximately $420 \mathrm{sq} \mathrm{ft}$ is designed for office space.

The Menlo Park facility provides for the Water Resources Division a place for research activities in ground water and quality of water. When the office is fully staffed it is anticipated there will be another four or five professional employees. One of the first studies to be undertaken will be a coordinated study by the two Branches in an effort to determine the effect of water quality on the growth of phreatophytes. It is believed that other studies of mutual interest to both Branches will be undertaken in the Menlo Park space.

The Quality of Water Laboratory has been furnished with special regard to research activities. The laboratory furniture and equipment is installed in three laboratory rooms. There is also available a storage room for laboratory equipment and supplies. Space for the Division's analytical balances is available in a separate room which may be entered directly from the laboratory space. A unique feature of the specially designed balance room is that the floor of the room is the top of a concrete record storage vault and there is no physical connection between the floor and the side walls of the balance room. The rigidity of the floor and the isolation from the walls gives an almost perfect floor on which balance tables can be set. The laboratory equipment includes two of the recently developed Gram-atic balances.

The smallest of the laboratory rooms has a workbench down one side and a hood and shorter workbench with a chemist's desk on the other side. The hood sets' against the wall of the "two-man laboratory" so that exhaust pipes from the two hoods and electrical and gas connections were easily made. The two-man laboratory has a workbench down one side with a hood, pegboard, sink, and chemist's desk. In the hood a water bath has been set up and two units of infra-red heating lamps have been installed. These lamps will be used to burn off filter papers and to evaporate water samples. In the center of this larger room there is a wide workbench with a sink at one end and a large bottle of distilled water is mounted on the framework behind the sink. On the further wall, storage cases are available for glassware and other equipment and for a chemist's desk. At the end of the laboratory, away from the window, there is a storage dispensing cabinet for chemicals. In a corner of the room, beside the chemical storage case, a small refrigerator and an oven have been installed.

The third laboratory room has been designed for instruments. It has no natural light but is well equipped with artificial light and can be used for determinations where a dark room is desired. The Beckman spectrophotometer with its flame attachment and photomulti plier sits in one corner of this room under a canopy which has an exhaust fan. A small water still has been set up in this room, and there are work tables and storage cases.

This laboratory and of fice arrangement appears to be quite satisfactory for a small group of operating personnel and should prove a valuable asset to the facilities of the Water Resources Division.

\section{Surface Water Instrumentation Research Unit}

By Edgar G. Barron

(Engineer, Columbus, Ohio, sw)

The Instrumentation Research Unit of the Surface Water Branch, established during the past fiscal year, consists of two engineers at present: Hal Wires, electronic engineer, and the writer, supervising hydraulic engineer. It was anticipated that much of our future development work would be in. the electronic field. 
Hence, the electronic engineer was assigned and a small electronic laboratory set up in a front room of the Survey warehouse at 858 King Avenue, Columbus, Ohio. This laboratory is about a block from the Equipment Development Laboratory and the Surface Water district office. The latter office handles stenographic and bookkeeping work for the new unit. Mail should be addressed to U. S. Geological Survey, Instrumentation Research Unit, 1509 Hess Street, Columbus 12, Ohio. The telephone numbers are Walnut 9186 and Walnut 1602, the same as for the Columbus district office.

The Electronic Laboratory has all of the electronic equipment previously purchased for the Equipment Development Laboratory by the Surface Water Branch and additional items are being purchased as needed.

An important activity of this Research Unit is to maintain close liaison with other government agencies that may be interested in the same problems, and with private research and instrumentation companies that may be capable of and interested in developing new types of equipment that will solve some of our problems. Only minor design and development work will be done in the Electronic Laboratory; it will be used mostly to test and seek improvements in new electronic equipment as it is delivered and prove it practical before field installations are made. It is likely that maintenance of new electronic equipment in the field and training of field employees in its use and maintenance will become a major activity of the Unit in the future.

Another aim of the Unit will be to visit district of fices as frequently as possible, in order to keep abreast of their instrumentation problems and to inform personnel of new instrumentation developments. As personnel of the Equipment Development Laboratory do not have the time or opportunity to visit district of fices as often as is desirable, we will be happy to acquaint field personnel with their development work and to carry cirticisms and suggestions back to them from the field.

We will collaborate with the Equipment Development Laboratory on equipment that is developed for the Surface Water Branch. Several of these items which are active at present are:

1. Conversion of Stevens continuous recorder to shift time scales automatically, from perhaps 1.2 to 4.8 or 2.4 to 9.6 inches per day when above a selected gage height, with positive assurance that recorder will continue to operate at the base rate in event of failure to shift. This will be particularly useful on the many small-basin stations that are being established in most districts at present.

2. Development of one or several types of "package" or "Roving" gage wells and shelters that can be installed and operated at one site for several years and then be moved economically to another site when the short-term study at the first site is completed.

3. A trial installation of a bubbler-type recording gage on a nearby stream for test purposes. The bubbler-type gage eliminates the stilling well entirely and operates on the principle that, if a gas (possibly $\left(\mathrm{CO}_{2}\right)$ is bubbled slowly through a small tube and discharged at a fixed elevation under water, the pressure in the system at any level is that due to the depth of water less the equivalent weight of the gas column. If our ideas for compensating for variations in the weight of the gas column with variation in pressure and temperature (and several other sources of error) are success ful, the system would not be 'imited to a small range in stage as in present commercial installations. Recording the change in water level (with great accuracy) as reflected by change in pressure in the system at the recording level, is a serious problem, and we have several methods of doing this under consideration.

4. A vertical-vaned rotor to replace the existing cuptype wheel of the Price meter. It is hoped that this rotor can be designed to eliminate most of the effects of vertical components of the velocity and allow precision molding or die-casting in either plastic or metal so that final models are reasonable in cost and identical so as not to require individual ratings.

A small tank (perhaps 16 feet long) for hydraulic testing is planned for installation in the warehouse back of our laboratory. This tank will have an electrically driven carriage on accurately machined track that will carry the item being tested at low velocities through still water. It may also have a vertical divider down the center to within a foot or two from each end, and suitable vanes to conduct the water smoothly around the ends so that one side can be provided with a pump to circulate water around past a test section on the other side.

Preparation of specifications for a development contract for an electronic river-stage recorder has been completed and invitations to bid on it will be sent out from Washington soon. The invitations request development of a river-stage recorder that will not require a stilling well, will operate from portable, readily available dry batteries, as well as from powerlines, and will meet our usual standards of accuracy of recording at the site and ease of telemetering to distant locations.

An electric low-velocity meter has been obtained, and preliminary tests have been made of it at the University of Illinois. These tests indicate some instability of rating below about 0.05 foot per second. We hope that further improvements will eliminate this instability and give us a practical meter that will accurately measure velocities considerably below the range of the Price-type meter.

Many interesting possibilities are suggested by the electronic companies. These range from methods of recording river stages through air without anything touching the water to methods of recording the mean velocity on a line across a river. No one expects practical developments to come easily that will replace our tried and true methods and instruments. Some leads will undoubtediy prove false, but we hope to be in on the ground floor in the many hydraulic instrumentation developments that apparently lie just ahead. 
Appendix V--Bubbler-Gage Development

By E.G. Barron and H.O. Wires

(Water-Resources Bulletin, November 10, 1955) 


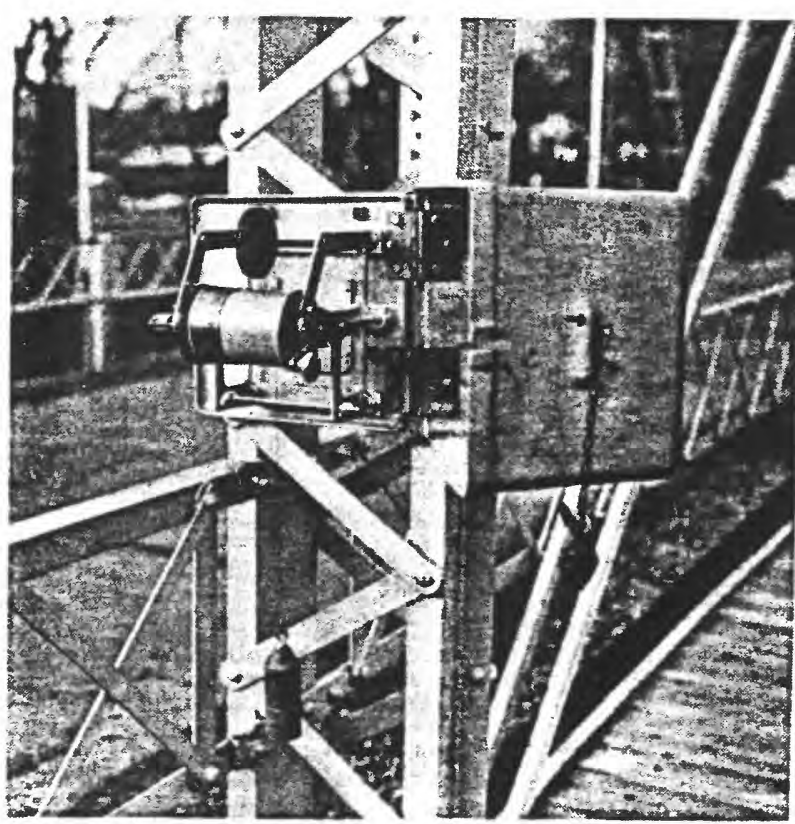

Figure 1.-Reversed Type-A wire-weight gage.

ratchet to hold. A spring arrangement to bring it up and hold it in position was considered and discarded as being clumsy and probably ineffective. A new pawl was designed and made from $\frac{1}{4}$-inch strap steel. It bolted into place where the old pawl was removed but arched up over the ratchet and engaged it with a hook from above rather than directly with a butt stop as the original arrangement provided. Then the index wheel pointer was moved from the right end frame to a similar position on the left end frame. Two small holes were drilled in the left end of the drum to provide an anchor for the wire. The wire was rewound from the left end, and the weight was attached. The gage is now in use at Perintown.

Jere B. Scott, Meterorologist U. S. Weather Bureau

\section{Bubbler-Gage Development}

By E. G. Barron and H. O. Wires

(Engineers, Instrumentation Research Unit, Columbus, Ohio, SW)

\section{Synopsis}

One of the principal problems of Surface Water is the recording of river stages. Stilling wells for float-operated recorders are costly to construct, troublesome to maintain, and usually cannot be moved economically from one site to another. A bubbler-gage, using the gas-purging technique, has been developed to eliminate the stilling well and to drive a standard recorder to follow a river level within 0.01 foot. The gas pressure from the bubbler is sensed by a special mercury manometer follower that, in turn, operates the recorder.
Several methods of recording river stages without conventional-type stilling wells are under consideration or development by the Instrumentation Research Unit (I. R. U.), Surface Water Branch. Southwest Research Institute is working under a contract to develop an Electronic river-stage recorder (Vibrotron) using a sensitive pressure transducer. The Columbus Equipment Development Laboratory has built an experimental model of an electrical float switch for Ground Water, which may be useful also to Surface Water, for recording the level in a small ( $1 \frac{1}{2}$-inch) vertical pipe. Two firms are working on somewhat similar devices to record the level in relatively small-diameter pipes mounted both vertically and inclined.

The writers, comprising 100 percent of the I. R. U. staff, have developed a bubbler gage in their spare time that shows promise of practical field application. The fact that the bubbler system is self-purging (river water does not enter the system) may make it particularly desirable in sediment-laden streams.

For the benefit of those that have not been introduced previously to the bubbler technique, we will discuss its principles briefly and describe our method of applying the system to river-stage recording. [See also articles by Graham and Conklin $(250$, p. 12) and Loh$\operatorname{man}(1153$, p. 97).1

If a gas is bubbled slowly through a tube and discharged freely into water at a fixed elevation, the pressure in the tube, at any elevation, is that due to the depth of water over the bubble orifice, except for m1nor differences due to the weight of the corresponding column of gas and to friction in the tube. As the gases we might use are practically weightless compared to water, the gas-purging system gives us a means of transferring the orifice pressure to a recording point above flood level. The gas is not completely weightless, but the problems caused by this will be discussed with the description of the instrumentation.

The self-purging feature of the bubbler technique is attractive. What stream-gager has not wished that all wells were in Hades each time he had to clean one? The first problem was to find a practical method of recording stage accurately from the gas pressure. Except for the Vibrotron referred to above, we could find no pressure-sensing device that met our accuracy and range of stage requirements. The best accuracy offered by such devices is about 0.5 percent of full scale. If our full scale is 50 feet, the accuracy would be \pm 0.25 foot.

Fischer and Porter Co. make a PRESS-I-CELL which appears to have sufficient accuracy for our needs, except possibly temperature effects, but the cost of one adapted to operate a water-stage recorder was almost $\$ 3,000$. The Fanger Research Laboratory makes a mercury manometer which also could be used but one with necessary temperature compensation would cost about $\$ 3,000$, could be operated only from a $-c$ current, and is more of a laboratory then field instrument.

Because we could not find a reasonably priced device that met our requirements, we have designed a manometer and follower (fig. 1) which drives an A-35 recorder to follow a gas pressure to within $0.0032 \mathrm{psi}$ $(0.01$ foot of water). The range of the first model is 
20 feet but this is being extended to 40 feet in a second model. The follower is designed to operate for long periods on two 6 -volt, hot-shot batteries for the drive motor and two small 90 -volt dry cells for the sensing circuit. Power is consumed only when the: stage is changing and is limited to less than 1 watt, which will allow very economical operation.

Figure 1 shows the manometer follower operating an $\mathrm{A}-35$ recorder in our test setup in the laboratory. Below the table at the right is a cylinder of nitrogen with conventional pressure regulator that can be set to reduce the more than 2, 000 -psi tank pressure to approximately $50 \mathrm{psi}$. This pressure is conducted to a constant differential regulator which is visible below the table at the left. The constant differential regulator performs the very necessary task of feeding gas to the system at a slow, constant rate, which can be adjusted as desired in the visible-feed chamber, regardless of the pressure drop across it. The two regulators, when set, maintain the desired bubbler rate automatically, regardless of variations in backpressure from the river and cylinder pressure (system will operate unchanged as long as the cylinder pressure is more than 3 psi greater than the water pressure in the river).

One of the two $1 / 8$-inch copper tubes leading out of the upper left corner of figure 1 carries the gas to the discharge orifice in the water. The second tube is also filled with gas and senses the pressure back from near the orifice to the recording point and eliminates the effect of any variation in the friction in the tubes. In small installations, where the length of tube is not more than about 50 feet, a single tube may be used because possible variations in the friction of the gas flowing in the tube will be negligible.

Figure 2 pictures the plastic standpipe in our laboratory which is used to test various water-level indicating and recording devices. It has been very useful in testing the bubbler gage and devising simple methods of determining the necessary bubbling rates in future field installation of this equipment. In figure 2 the copper bubbler tubes come down along the plastic standpipe to a tee just below the control shelf. The single tube leading on down enters the center of the 2 -inch pipe plug and discharges the bubbles of gas at that point into the water in the standpipe. The control box on the shelf operates solenoid valves (one can be seen at the base of the standpipe) to fill or drain the standpipe at rates that can be adjusted by gage valves to simulate changing stage in a river. Manual operation is provided by pressing the buttons as desired. The control can be switched to automatic and cycle the water up and down continuously in the standpipe between the lower electrical contacts (which can be seen attached to both sides of the standpipe about 10 inches above the rectangular base) and a similar pair of contacts about 10 feet higher, near the top of the pipe. The electric tape gage is rigged to read the water lev$\mathrm{el}$ in the standpipe. A plunger and diaphragm are attached to the center front of the rectangular base to produce surges in the water in the standpipe. Since the picture was taken, a variable speed drive and gear reduction have been added so that any amplitude and frequency of surge can be produced.

Another source of error, which must be considered in the bubbler technique, is the variation in the weight of the gas with temperature when the recording point is high above the water. For instance, if the mean temperature of the pressure-sending tube along its length (through the ground, etc.) varies from an assumed air temperature of $70^{\circ} \mathrm{F}$ by as much as $30^{\circ} \mathrm{F}$, with the stage at 2.0 feet above the orifice, the error per foot of total height would be approximately 0.00007 foot. In this example, if the equipment were 100 feet high the error would be about 0.007 foot. Of course, the error would be proportionately greater at higher stages, if not compensated for, but we are interested in the greatest accuracy at low water. In a slope reach, such errors would cancel if bubbler gages were installed at each end of the slope reach and at about the same height above water.

Any pressure-sensing system for recording water levels will be subject to errors because of variations in the density of water due to temperature and chemical and sediment content. Here again we have one advantage, at least, because density-produced errors will vary with stage and will be negligible at low water. Moreover, the intakes of conventional stilling wells are in effect pressure-sensing devices and affected in somewhat the same manner because the density of the water in the well is not always the same as that in the river. In fact, our manometer follower can easily be adjusted to compensate for average variations of density with relation to stage. Obviously, sediment content will vary somewhat with stage - at least we would not normally expect extreme concentrations of sediment at low stages. Density of water does not vary appreciably with temperature until above $60^{\circ} \mathrm{F}$ and approaches 0.5 percent at $90^{\circ} \mathrm{F}$. Density variations with chemical content of the water in fresh-water streams should not be enough to be troublesome.

You will notice (fig. 1) that the gas pressure from the static pressure tube is exerted on the mercury surface in the lower plastic cup which rides on rollers (ball-bearing races) on an accurately machined and inclined surface. Any change in pressure (change in river level) causes a small amount of mercury to flow through the flexible, plastic tube which connects the two cups. The change in the mercury level in the upper cup (vented to atmosphere) causes a small stainlesssteel float to tip up or down on jeweled bearings causing the stainless-steel rod (armature) that extends upward, to move horizontally between two noble-metal contacts. As the stage rises, increasing pressure causes the armature to move slightly to the left producing light contact pressure, which operates the polarized relay on the small box at the left end of the recorder. As the relay is energized the small motor back of the contact assembly rotates the threaded shaft; this moves the lower chamber downward until the difference in the mercury levels corresponds to the change in pressure. Decreasing stage causes the lower chamber to move upward in reverse manner, maintaining a constant state of equilibrium. The point setting in the contact assembly can be adjusted to give the desired sensitivity ( \pm 0.0005 inch of mercury which is equivalent to \pm 0.005 foot of water). Various motor speeds can be provided to follow any desired rate of change.

As the threaded shaft rotates, the worm and gear drive the recorder, and the small spur gears drive the counter, so that each follows the river level as it changes. The counter replaces the well gage and we believe it will be satisfactory for the purpose. 


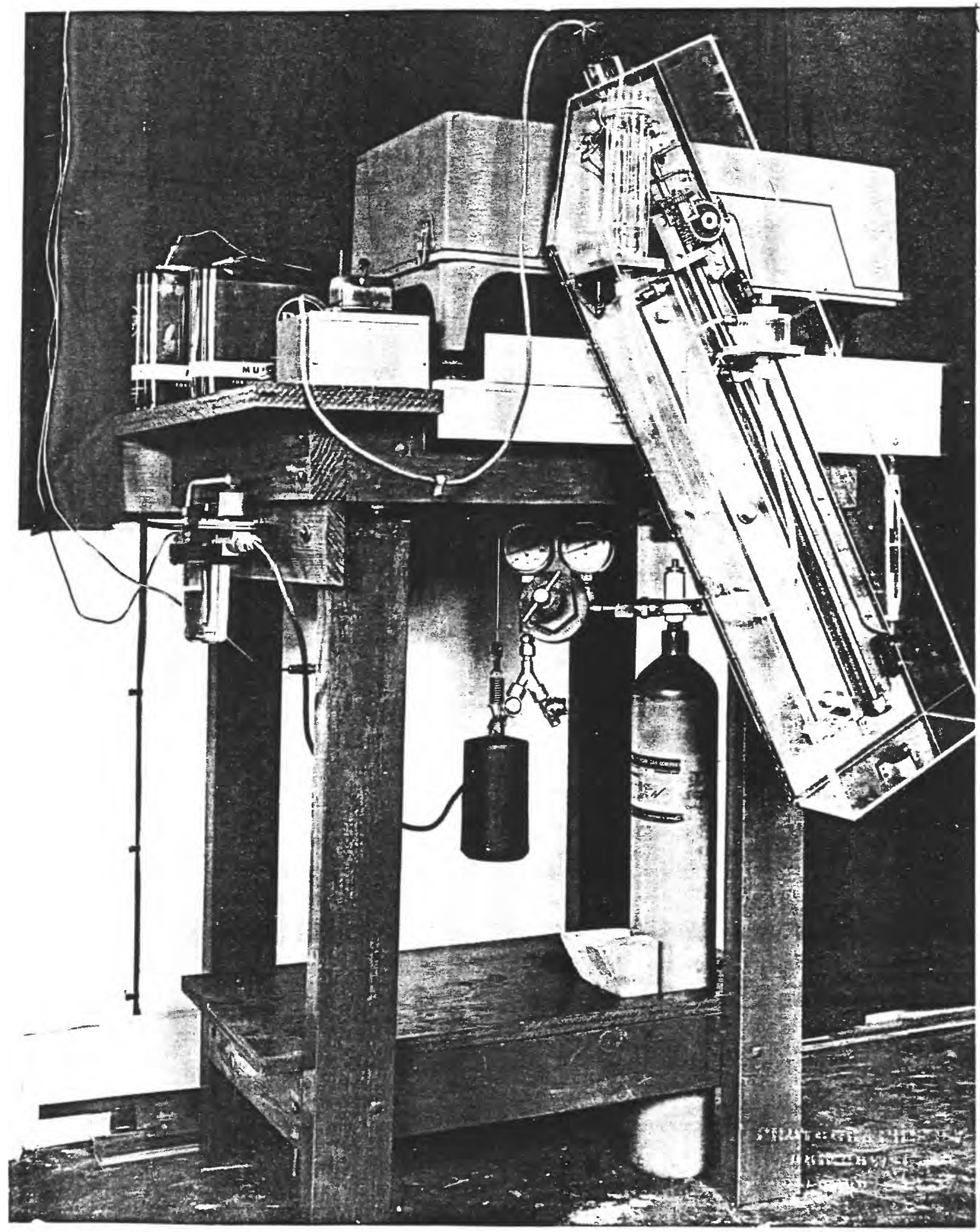

Figure 1. - Laboratory bubbler-gage installation. 


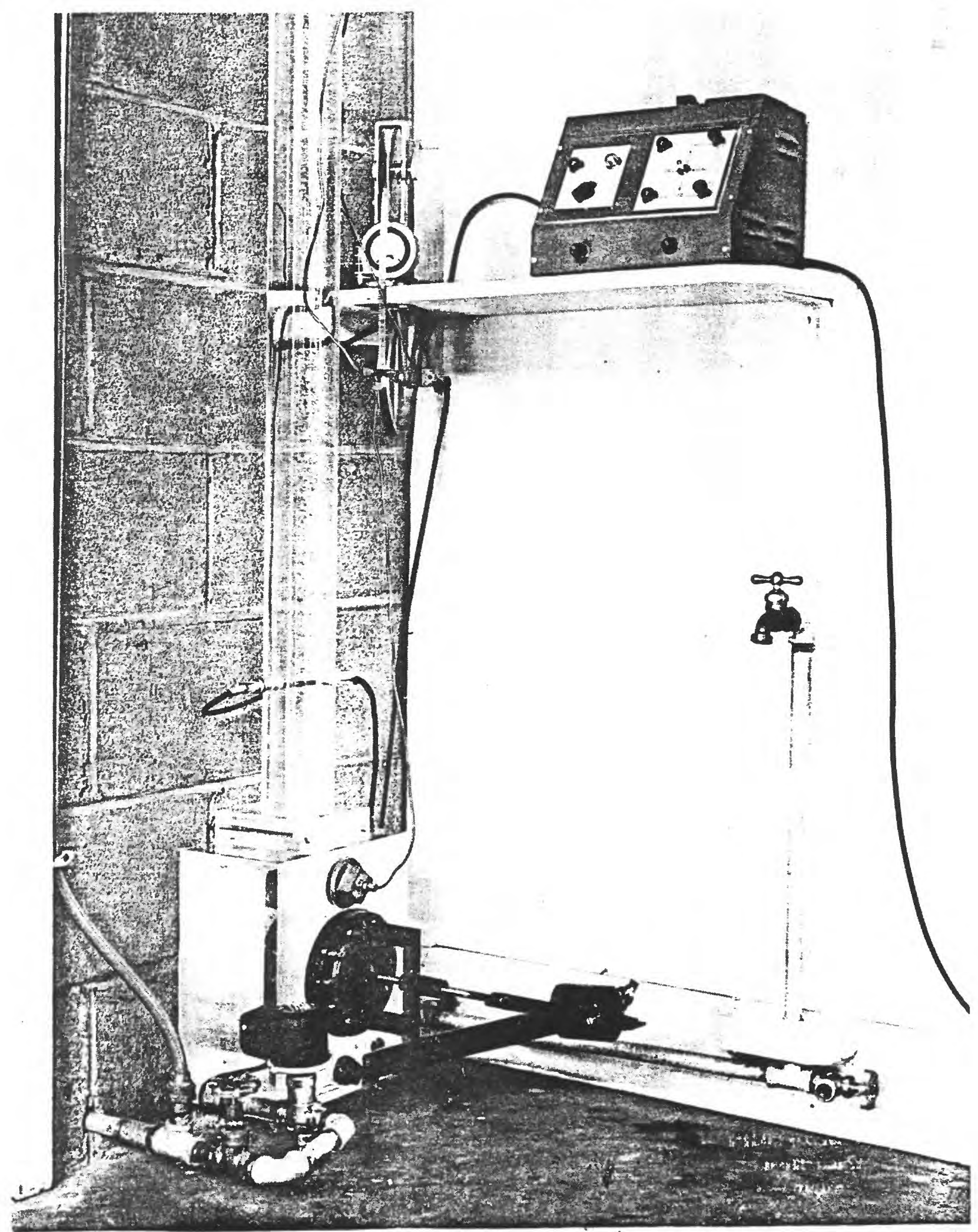

Figure 2. - Test standpipe in laboratory. 
The entire manometer assembly is suspended at a particular angle (approximately $28^{\circ}$ from vertical in this model) to simplify gearing to the recorder and the counter. This feature permits compensation for anything that varies with stage, such as the weight of the gas in the tubes and density of the water (insofar as these vary with stage) by slight changes in the angle of the assembly.

A conventional vertical manometer would require considerable temperature compensation because mercury has a much higher coefficient of thermal expansion than any of the materials that might be used for the manometer tubes, such as glass, plastic, or stainless steel. However, the combined surface area of the mercury in the plastic cups of our manometer is so large in relation to the total volume of the mercury, that differential expansion of the mercury and the plastic, with both temperature and pressure, has a negligible effect on the surface levels.

Surges in rivers would keep the follower hunting continuously and exhaust the batteries at an unnecessarily rapid rate. A delay circuit, therefore, has been provided that operates on 0.04 watt, and this only when energized. It has a particularly desirable characteristic for this purpose as the first delay is long when the stage changes, and as the stage continues to change in the same direction, subsequent delays are relatively short. However, if the change reverses, the first delay will again be long. Thus, the follower responds faithfully to true changes in stage but the delay circuit can be adjusted to almost eliminate the recording of undesirable surges.

The amount of gas that must be fed to a given bubbler system, to eliminate lag in recording, depends on the volume in the system (bubbler tubes, manometer, etc.) and the maximum rate of increase in stage that is expected. It is only necessary to feed gas to the system when the stage is rising, but it would increase the cost and complication of the device to include a means of automatically varying the gas feed. It may be practical, however, to automatically stop the flow of gas during recession periods. Another possible method to save gas, if justified, would be to use the regular needle valve to adjust the exceedingly slow feed necessary during low stages, and then provide a bypass line (with a suitable orifice) that would be opened electrically at a selected stage to provide the necessary increase in feed rate when the stage might rise at accelerated rates.

The first model bubbler gage was installed recently at a regular gaging station on the Olentangy River north of Columbus. The bubbler orifice was placed at the center of the regular $2 \frac{1}{2}$-inch lower intake pipe and about 9 inches back from the outer end. The bubbler, therefore, senses the pressure in the regular stilling well intake and its record can be directly compared with that from the standard float-operated recorder. So far, in the laboratory tests and during this limited trial in the river, the bubbler gage appears to give at least as accurate a record as the usual float-operated recorder.

During the next several months the first model bubbler will be operated continuously on the Olentangy River. A second 40 -foot range model will be built and tested in oli: laboratory. About four additional models will be produced for installation in the field next summer. These will be placed in districts that have special problems in stage recording that cannot be solved practicably by stilling-well installations.

It appears that the bubbler gage will meet our accuracy requirements. Dry batteries and cylinder gas must be provided, but a properly designed system will operate for long periods without replacement of these items. Batteries and gas cylinders will be small and light enough for packing in to remote locations. The system may appear quite complicated from the above description, but it can be easily serviced by fieldmen, once they become familiar with it. It is likely that the cost of a bubbler-gage installation will compare with the cheaper of our regular stilling-well installations. A bubbler gage might be installed complete on a small or medium-sized stream for about $\$ 1,500$, and the cost for larger streams would not be much greater. The equipment could be moved to another site with very little "left in the ground" at the first site. The self-purging feature should eliminate the difficulties of wells and intakes filled with sediment.

\section{HYDROLOGIC INVESTIGATIONS}

\section{World's Greatest Rainfalls and Some Recent Texas Floods}

By D. E. Havelka

(Engineer, Austin, Tex., SW)

Occasionally we get a station rated almost as high as the stage has ever been since the Comanches were around and think that we have done pretty well. Then we get a whopper of a flood, the peak stage is exceecied almost 10 feet, and the peak discharge is over double that of the historic flood. This situation occurred on one of our Texas stations, the Pedernales River near Johnson City. The maximum stage known was about 33 feet in July of 1869 , which would give a discharge of $210,000 \mathrm{cfs}$ according to our present rating. But the flood of September 11, 1952, had a peak stage of 42.5 feet and a peak discharge of $441,000 \mathrm{cfs}$, which was 9.5 feet higher and 2.1 times greater than the 1869 flood.

We thought the flood on the Pedernales River had set some sort of a record, but then along came the Rio Grande flood of June 1954 and we get some fantastic stages. The maximum stage known since 1893, up to May 1954, on the Pecos River near Comstock, Tex., was 38.2 feet in 1932. The flood of June 1954 had a peak stage of 97.8 feet, which was 59.6 feet higher than the 1932 flood. The peak discharge of the 1954 flood was probably five times the previous record discharge of $116,000 \mathrm{cfs}$. The question comes to us, "How much greater could these floods have been?" Meteorologists can place contingency upon contingency and arrive at the maximum possible precipitation for any location, and from that others can estimate the maximum possible flood. As rainfall causes floods in Texas, we should look at what the maximum amounts and rates of rainfall have been. The Hydrometeorological Section of the U. S. Weather Bureau has plotted World's greatest observed rainfalls, as shown in figure 1 , in the January 1950 Monthly Weather Review. Since the D'Hanis, Tex., rain of 22.00 inches in 2 hours and 15 
Appendix VI--Edgar G. Barron and Harold 0. Wires, Patent No. 2,942,466 Motored Manometer for Indicating and Recording Fluid Level Variations

(United States Patent Office, June 28, 1960) 
June 28, 1960

Filed Oct. 30,1956
E. G BARRON ET AL MOTORED MANOMETER FOR INDICATING AND RECORDING FLUID LEVEL VARIATIONS

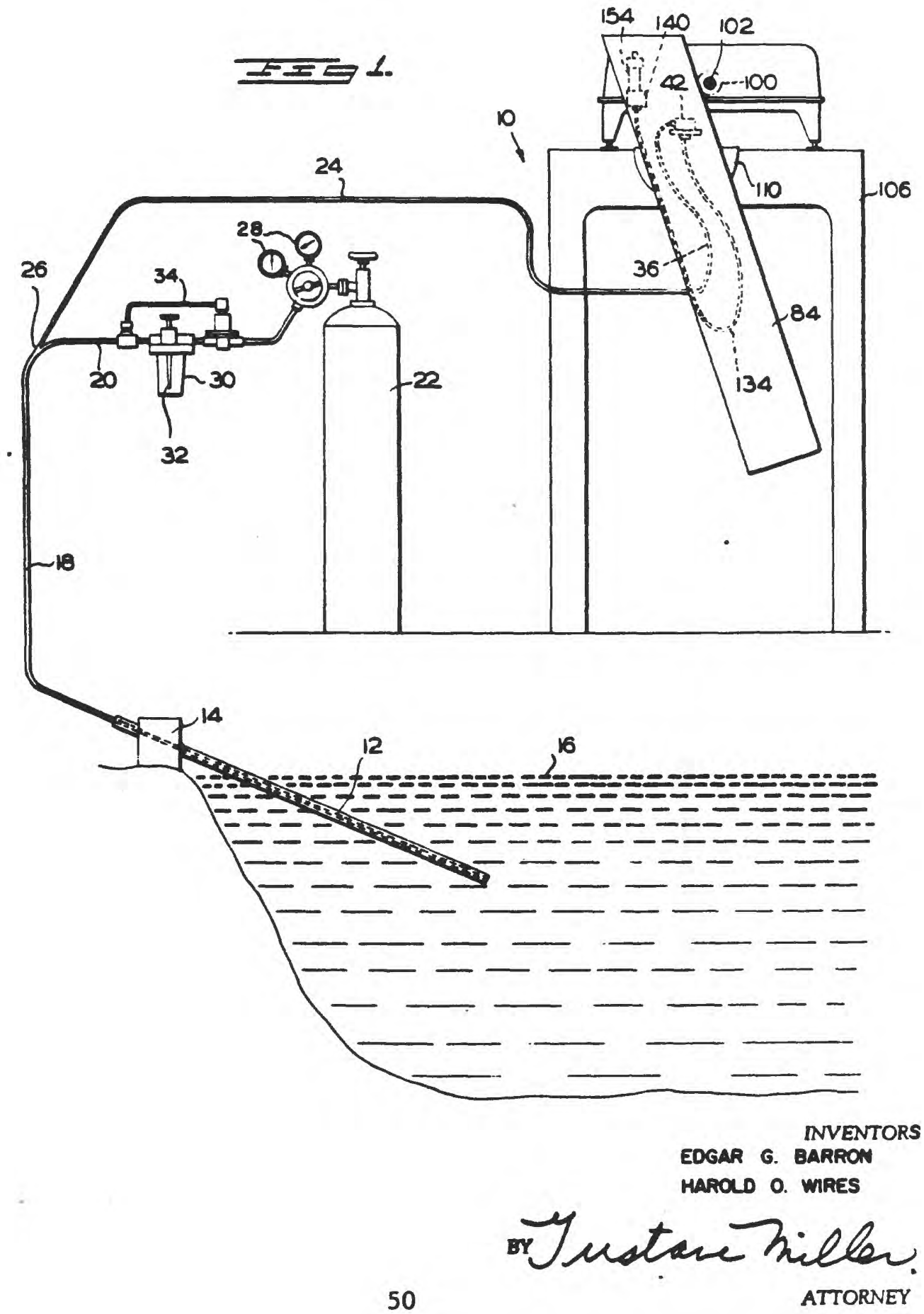


June 28, 1960

F1led Oct. 30,1956
E. G. BARRON ET AL MOTORED MANOWEIER FOR INDICATING AND RECORDING FLUID LEVIL VARIATIONS
$2,942,466$

6 Sheets-Sheet 2

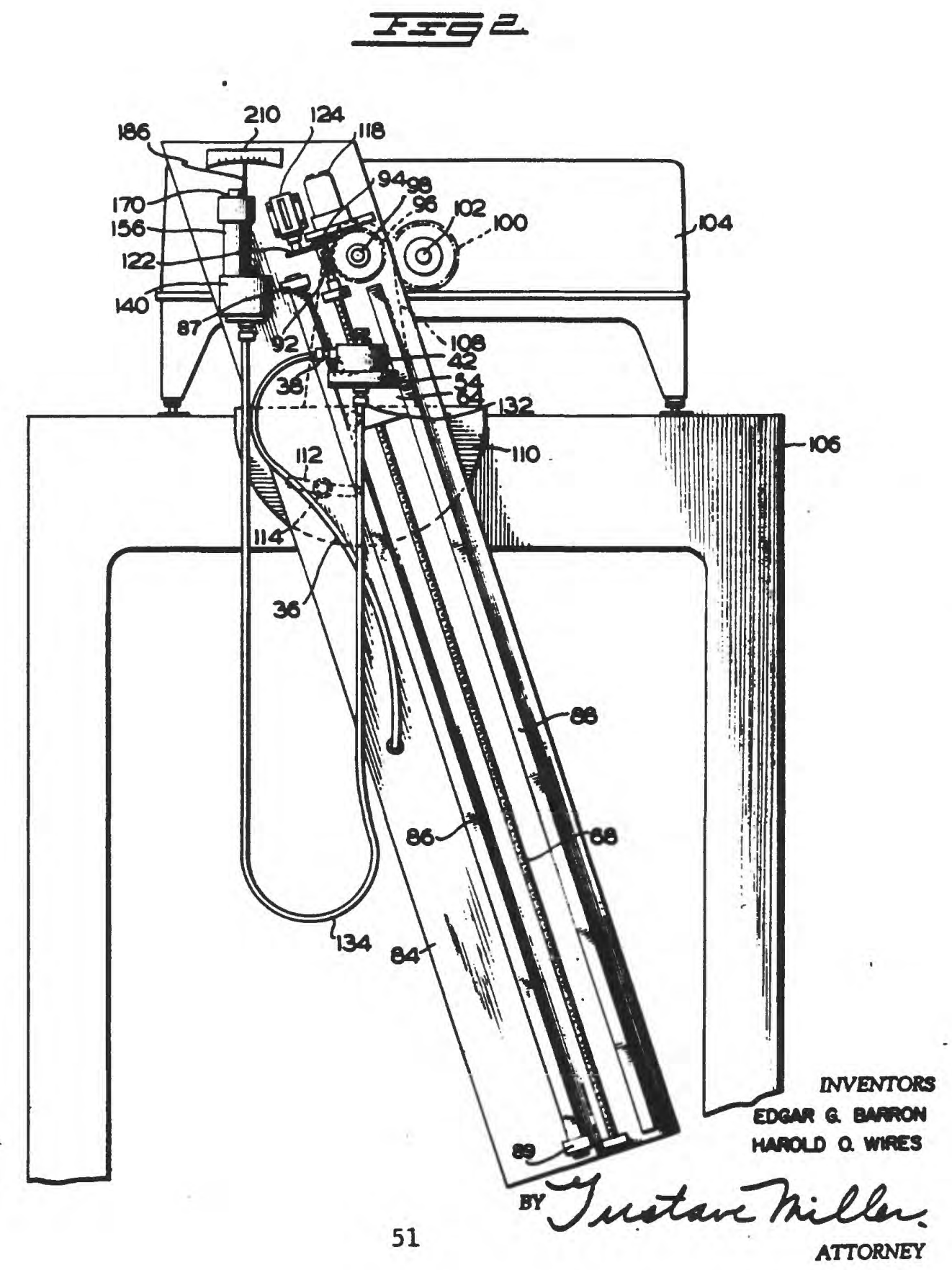


June 28, 1960

F1led Oct. 30,1956
MOTORED E. GANOMETER FOR INDICATING AND RECORDING FLUID LEVEL VARIATIONS
$2,942,466$

6 sheots-Sheet 3

포드 3.

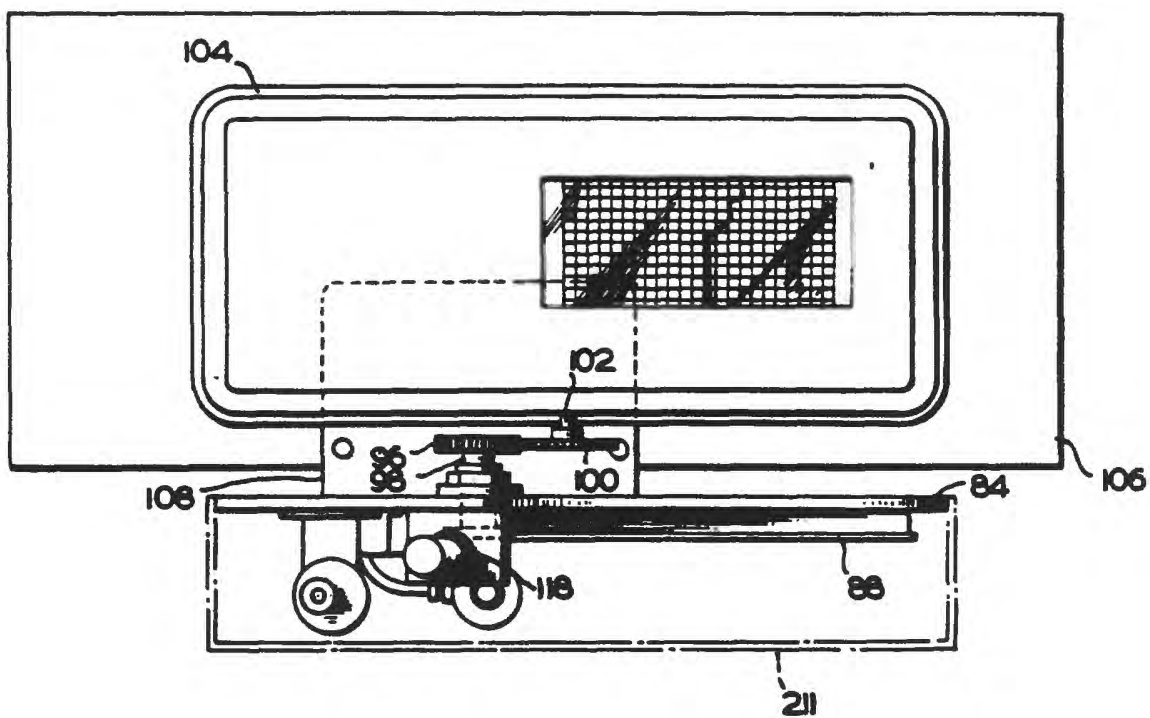

포르.

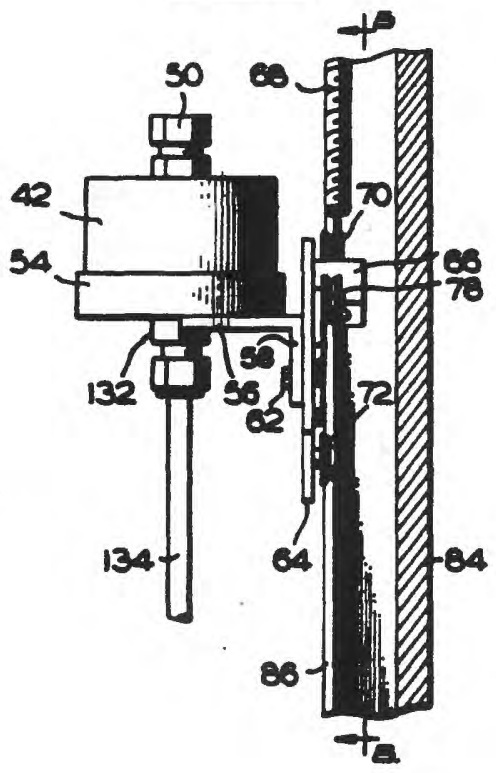

포르요

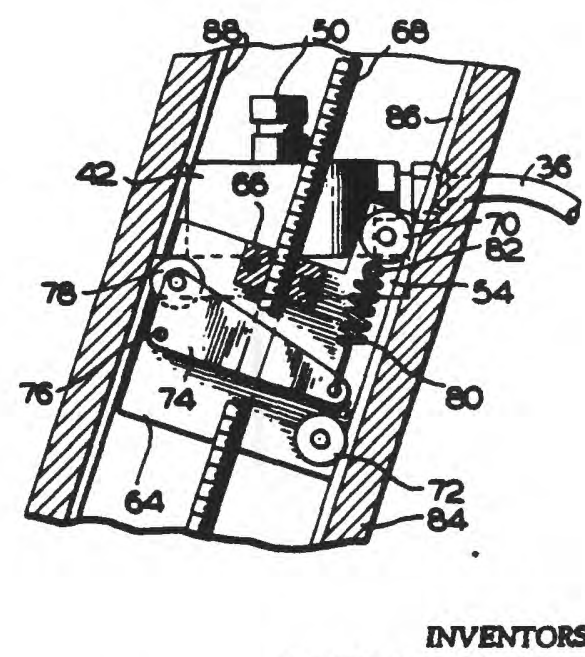

EDGAR G. BARAON HAROLD O. WIRES

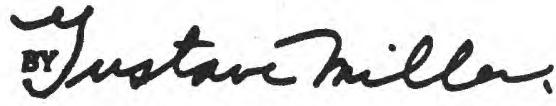

ATTORNEY 
June 28, 1960 EOTORED G. GARARON ERT AL
RECORD ING FLUER FOR INDICATING AND

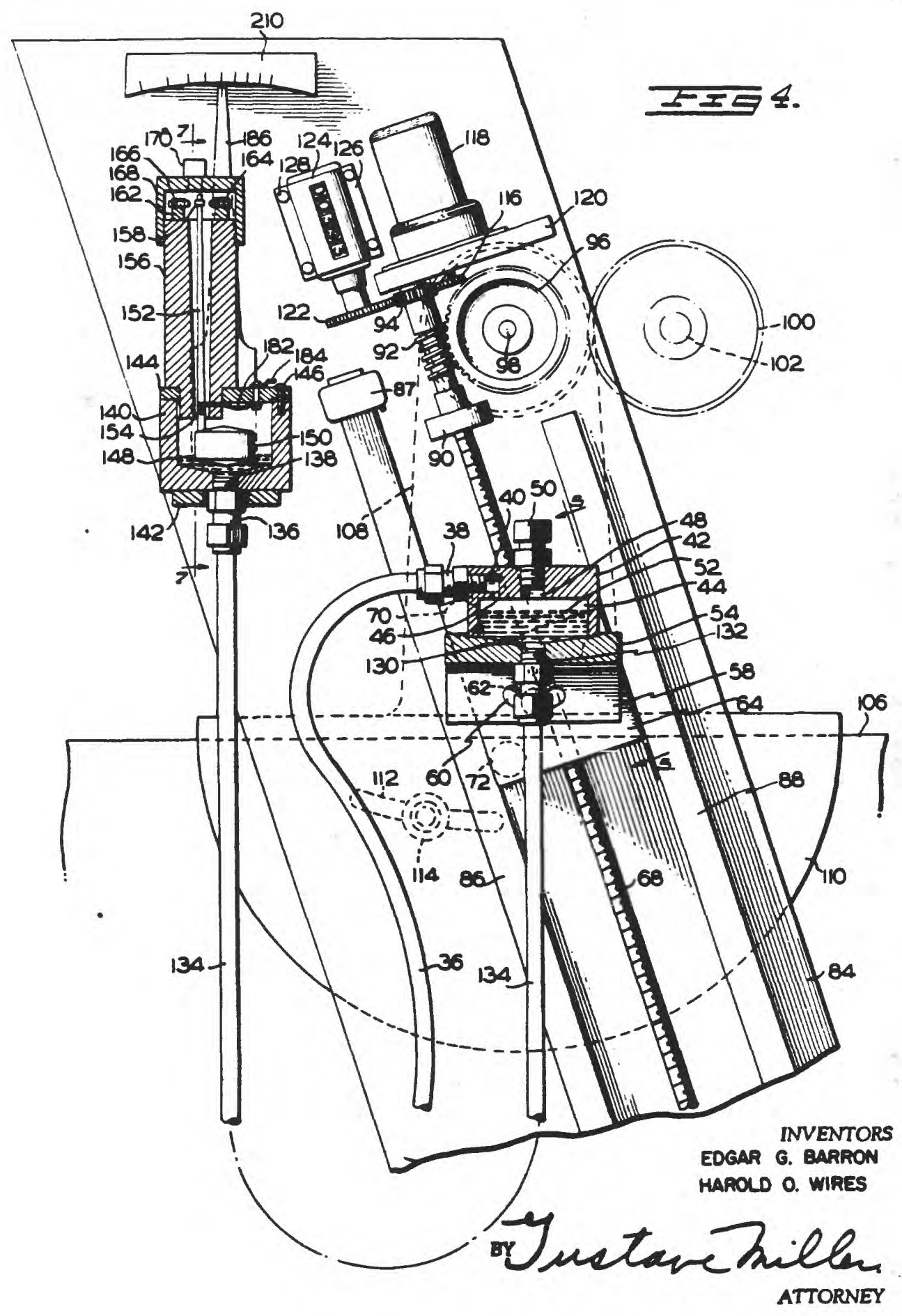



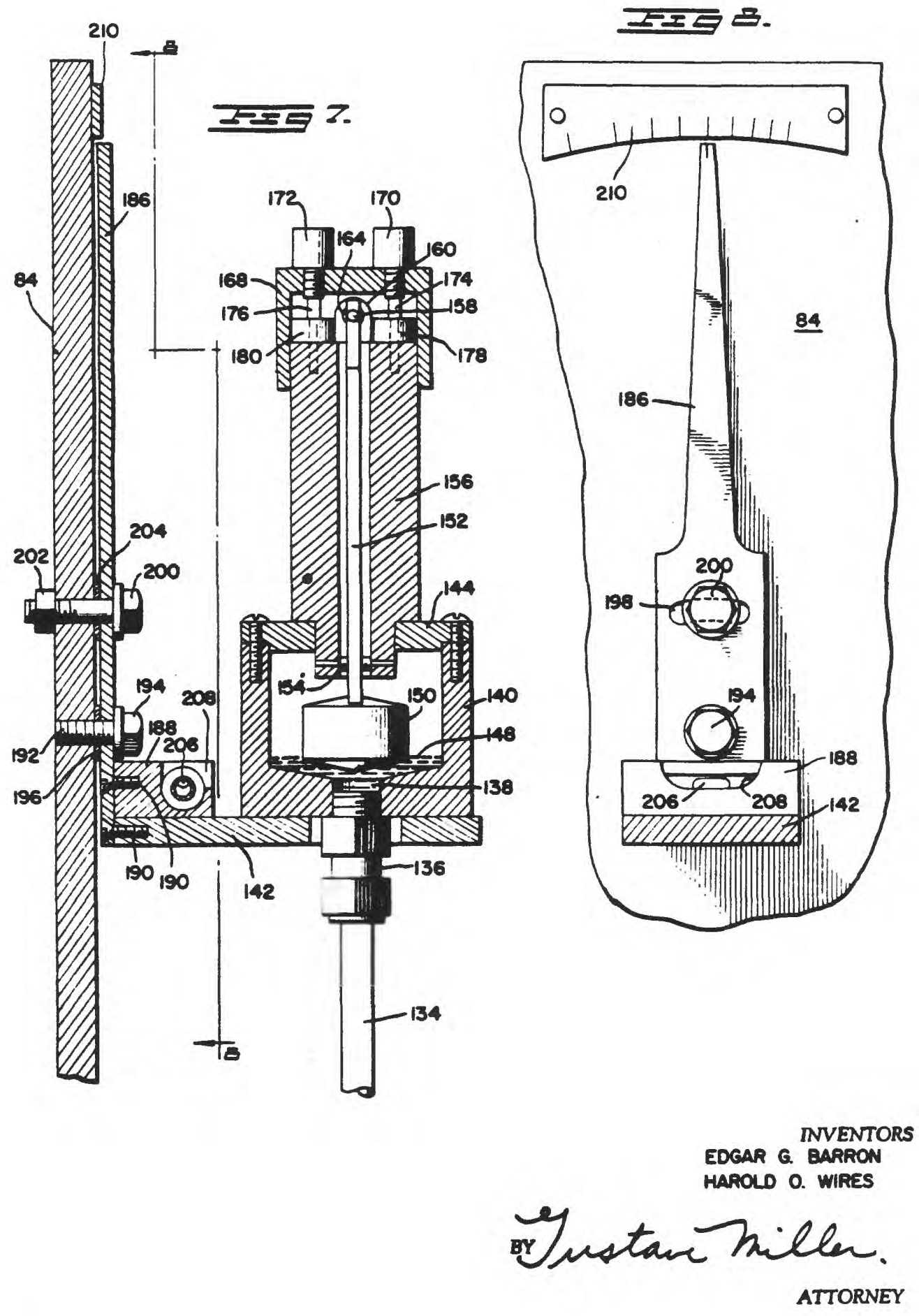
June 28, 1960

Filod Oct. 30,1956
E. G. BARRON ET AL MOTORED MANOMETER FOR INDICATING AND RECORDING FLUID LEVEL VARIATIONS

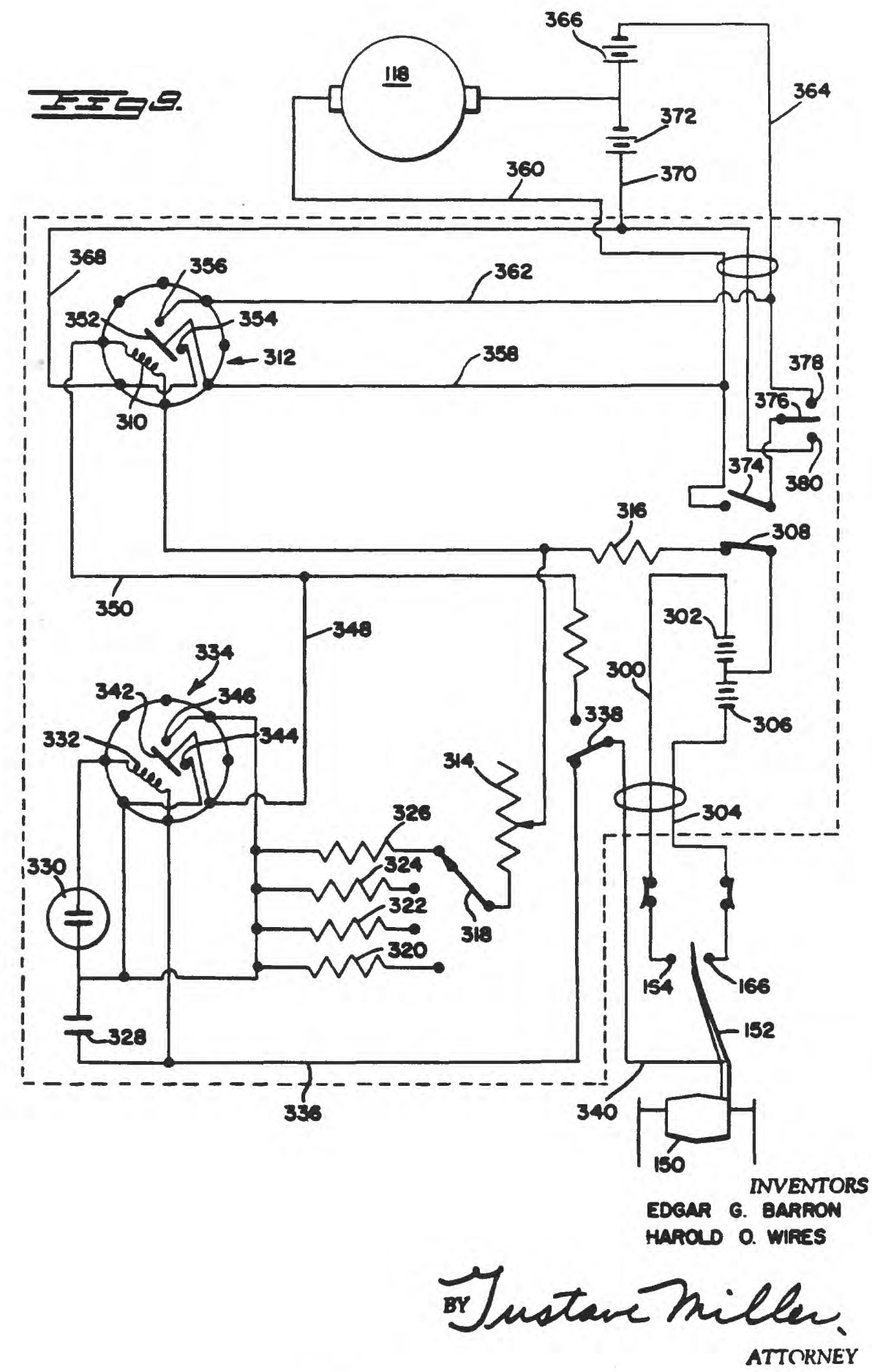




\section{2,942,466} MOTORED MANOMETER FOR INDICATING AND
RECORDING FLUID LEVEL VARIATIONS

Edgar G. Barron and Harold O. Wires, both of \% Harold O. Wires, 1509 Hess St., Columbes, Ohio

Flled Oct. 30, 1956, Ser. No. 619,246

15 Claims. (Cl. 73-302)

This invention relates to a pressure recording system, and it particularly relates to a system for measuring the water level of a body of water by means of a pressure differential.

The types of measuring and recording systems heretofore used were not completely adequate for accurate measurement because of the inherent mechanical deficiencies in the equipment. They were, furthermore, not sufficiently sensitive to record very small, but yet significant variations in the water level.

In addition to the above, the prior systems which generally included the use of a float and pulley arrangement, required the digging of wells at the side of the body of water, and such wells had to be dug as deep as the river, stream, or the like, would ever be expected to drop. This was not only time-consuming and expensive, but required the setting up of permanent installations which required continuous care and maintenance and which were useful only for the one particular body of water.

It is one object of the presemt invention to overcome the above and other disadvantages by providing a measuring and record-motored manometer system which can be used with any body of water, oil, or other fluid, and which can be transported from one area to another.

Another object of the present invention is to provide a measuring and recording motored manometer system for liquid !evel variations which can be adjusted to the local conditions, such as water or oil of varying densities, etc., easily and quickly.

Another object of the present invention is to provide a measuring and recording manometer system which is extremely sensitive to small variations and very accurate in its measurements.

Other objects of the present invention are to provide an improved measuring and recording system, of the character described, that is easily and economically produced, which is sturdy in construction, and which is highly eficient in operation.

With the above and related objects in view, this invention consists in the details of construction and combination of parts, as will be more fully understood from the following description, when read in conjunction with the accompanying drawings in which:

' Fig. 1 is a general, elevational view of the measuring and recording system embodying the present invention, showing it in operation while measuring the level of a body of water.

Fig. 2 is an enlarged, detailed, elevational view of recording apparatus.

Fig. 3 is a top plan view of the mechanism shown in Fig. 2.

Fig. 4 is an enlarged, fracmentary, view, partly in section and partly in elevation of the apparatus shown in Fig. 2.

Fig. 5 is a view, partly in section and partly in ele vation, taken on line $5-5$ of Fig. 4.
Fig. 6 is a view, partly in section and partly in elevation, taken on line $6-6$ of Fig. 5 .

Fig. 7 is a view, partly in section and partly in elevation, taken on line $7-7$ of Fig. 4.

Fig. 8 is a view, partly in section and partly in elevation taken on line $8-8$ of Fig. 7.

Fig. 9 is a schematic view of the relay control unit used to actuate the drive motor.

Referring now in greater detail to the drawings where10 in similar reference characters refer to similar parts. there is shown a motored manometer or measuring and recording apparatus, generally designated 10 , which includes a tube 12 mounted on a bracket 14 on the bank and extending into the upper surface of a body of water 16.

The tube 12 has a fluid connection through a tube 18 to a tube 20 leading to a source of fluid pressure which is, in this case, a tank 22 containing a gas, such as nitrogen, under pressure. The tube $\mathbf{2 0}$ is also connected to tube 24 which is, itself, an extension of tube 18. The intersection of the three tubes is indicated at 26.

A pressure indicating dial system 28 is interposed in the tube 20. Also interposed in this tube is a trans25 parent housing 30 having a needle valve 32 . This needle valve permits a small amount of gas to bubble through the housing which acts as a sight feed to indicate the flow of the pressure fluid through the line. A by-pass conduit 34 is provided to equalize the pressure 30 on both sides of the sight feed. The flow of pressure fluid is indicated in the sight feed by the bubbling action through a liquid which is preferably held in the housing of the sight feed. The pressure fluid, such as nitrogen, is maintained both in the tube 12 and in the 35 tob 24, which is connected to a conduit or tube 36. This conduit 36 is connected, at its upper end, to a nipple 38 extending from an opening 40 in a housing 42. This opening 42 is in fivid comection with a chamber 44 in the housing through an orifice 46. Another open40 ing 48 is provided in the housing 42; this opening 48 being threaded and acting as a filling means. A threaded plug 50 is used to close the filling opening 48 . The housing 42, itself, may be made of any desired material; however, it is preferably transparent to permit a view of the chamber 44. A pool of mercury 52 is maintained in this chamber 42.

The housing 42 is mounted on a supporting platform 54, and this platform $\mathbf{5 4}$ is, itself, mounted on a bracket 56 having a vertical flange $\mathbf{5 8}$ at one side. The flange 6058 is provided with an arcuate slot 60 through which extends a bolt 62 . This slot and bolt provides an arcuately adjustable means for connecting the bracket to a carriage in the form of the plate 64 . This plate 64 has a threaded nut portion 66 for threadedly receiving a 65 threaded shaft 68 . As can be seen, the housing 42 and its supporting platform 54 is angularly inclined to the plate 64 and the shaft 68 . Actually, the housing 42 is preferably positioned in a straight horizontal position while the plate 64 and shaft 68 are inclined at a pre60 determined angle, as will hereinafter be more fully explained.

The plate 64 is provided, at one side, with an upper roller 70 and a lower roller 72 . A lever 74 is pivoted to the plate, as at 76 , and holds a roller 78 at the oppo65 site edge of the plate from where the rollers 70 and 72 are positioned, the roller 78 also being intermediate the other two rollers. The end of the lever opposite the roller 78 is connected to a spring 80 , the other end of which is connected to the plate, as at 82 .

70 The plate 64 rides up and down on a supporting member or guide structure 84 and the rollers 70,72 and 78 ride on rails 86 and 88 on the supporting member 84 . 
In order to press the rollers firmly against the rails, the spring 80 resiliently urges roller 78 against rail 88 and this action, in turn, forces the opposite rollers 70 and 72 firmly against the rail 86.

The upper end of the threaded shaft 68 is rotatably supported in a bracket 90 and above the bracket support 90 , the shaft is provided with a worm 92 . At the upper end of the shaft 68, above the worm 92, the shaft 68 is provided with a gear 94 . The worm 92 meshes with a gear 96 mounted on a shaft 98 , and this gear 96 is, in turn, in mesh with a gear 100 mounted on a shaft 102 extending from a graphic recording instrument 104. This instrument 104 is of the ordinary type available commercially for making a continuous graph of data against time.

The instrument 104 is mounted on top of base or table, or the like, 106. This table 106 also supports the supporting member 84 for pivotal adjustment thereon by means of an arm 108 connected, at its upper end, to the rotatable shaft 98 , and connected, at its lower end, to a rocker 110 . The rocker $\mathbf{1 1 0}$ is provided with an arcuate slot 112 which receives the head of a bolt 114 on the side of the table. By loosening the bolt 114, the rocker can be pivotally adjusted one direction or the other throughout the arcuate length of the slot 112 . When the proper position is reached, the bolt is tightened to secure the rocker, and, therefore, the arm 105 and guide structure 84 , in adjusted angular position.

The gear 94, at the upper end of the shaft 68, meshes with a gear 116 mounted on the armature shaft of a reversible motor 118; this motor being supported on a platform 120 extending from the face of the supporting member 84. On its opposite side, the gear 94 is in mesh with a gear 122 mounted on the actuatiog shaft of indicator mechanism 124 which is provided with indicator numerals for 1/100 of a foot; this indicator mochanism being supported by flanges 126 secured to the guide structure 84 by bolts, rivets, screws, or the like, indicated at 128, and serves to indicate the liquid level at any existing moment.

The housing 42, containing the mercury pool 52, is also provided with an opening 130 on its underside. This opening 130 is threaded to threadedly receive a nipple 132. Depending from the nipple 132 is a conduit 134. This conduit or tube 134 is connected, at its opposite end, to a nipple 136 which is threadedly engaged in a bottom opening 138 of a housing 140. This housing 140 is mounted on a platfarm 142 connected to the face of the supporting member 84 , and is provided with a removable top wall 144 fastened by screws 146. This removable top wall permits insertion and removal both of a pool of mercury 148 and of a float 150. This float 150 is provided on the top thereof, eccentric of its axis, with a rod 152. This rod is pivotally connected as by a pivot pin 154, adjacent to its bottom portion, and extends through an elongated housing extension 156 rising from the top wall 144 of the housing 140. The rod 152 extends within the housing extension to the upper end thereof, and is provided, at its upper end, with a switch contact portion 158. This switch contact 158 is positioned between two oppositely-disposed blocks 160 and 162 having adjustable contacts 164 and 166 mounted therein. A terminal cap 168 encloses the upper end of the housing extension 156, and this terminal cap is provided with terminal plugs 170 and 172 having pins 174 and 176 in contact with pin jacks 178 and 180 in the housing extension 156. The bottom portion of the rod 152 is electrically connected by wire 182 to a contact member 184 on the wall 144 of housing 140 . These various contacts, plugs, pins, etc. provide the means for forming an eloctrical circuit between the switch contact 158 and the actuating nerwork for the motor 118.

The connection between the platform 142, supporting the housing 140, and the supporting member 84 is a pivotal connection as best shown in Fig. 7. This pivotal
$+$

connection is between a pointer 186 , connected to a block 188 on the platform 142 by means of screws 190 . The pivot point is formed by a fixed bolt 192 extending out from the face of supporting member 84 and through

( a corresponding opening in the pointer. The bolt head 194 holds the pointer on the bolt, and a washer or spacer 196 is provided around the bolt between the pointer and supporting member. An arcuate slot 198, shown in Fig. 8 , is provided in the pointer, above the pivot point, and 10 through this arcuate slot extends a bolt 200 releasably held in place in the member 84 by a nut 202. A washer 204 sursounds the bolt 200 between the pointer 186 and member 84. By means of this arcuate slot and bolt connection, the pointer may be held in adjusted position 16 around the pivot bolt 192.

The pivotal pointer 186 is used to readjust the level of housing 140, and consequently of the mercury pool 148 therein. A level indicator such as a tube of mercury, or the like, is provided at 206 in visible position 20 within the cut-out portion 208 of block 188. The angular adjustment of the pointer required to level the mercury is indicated on a scale $\mathbf{2 1 0}$ connected to the member 84 and coacting with the pointer.

A transparent housing 211 for enclosing the support25 ing member 84 and the parts supported therein is pivoted to one side of the housine.

In operation, the tube 12 as well as the tubes 24 and 36 are filled with gas, such as nitrogen, from tank 22. This gas maintains a certain pressure on the mercury 30 pool 52 in housing 42 which is sufficient to maintain the level of pool 148 in bousing 140 at a height where the toat 150 keeps pivoted rod 152 straight. In this position, contact 158 is between the two contacts 164 and 166 . When the water level in the body of water 16 increases, 36 it creates a pressure which forces up the gas into the chrmber 44 in housing 42 . This depresses the pool 52 , which acts through the mercury column in tube 134 to raise the level of pool 148 in housing 140. This raises the flont 150 and causes rod 152 to pivot to the left, as

40 viewed in Fig. 4. This brings contact 158 against contact 1C6 and, thereby energizes a circuit to a battery which causes the reversible motor 118 to rotate in one direction. The gear $\mathbf{1 1 6}$ on the motor shaft then acts through gear 94 to rotate shaft 68 in a direction to threadedly move the housing $\mathbf{4 2}$ downwardly relative to housing 140. When the null or balanced condition between the two mercury pools 52 in housing 42 and 148 in housing 140 is reached, the float 150 descends and moves the contacts away from each other. This stops the motor.

30 Limit switches 87 and 89 at the top and bottom of one rail 86 are provided in the path of the carriage plate 64 carrying movable housing 42 to prevent the carriage from overrunning the ends of threaded shaft 68.

During the operation of the motor and rotation of the 65 shaft, the gear 96 is rotated by worm 92 on the shaft and, in turn, rotates gear 100 to operate the stylus in the graphic recorder 104. At the same time, gear 94 rotates gear 122 to operate the indicator 124 which is calibrated numbers in $1 / 100$ of a foot, corresponding to the depth of the body of water 16.

If the water level is lowered, the reverse operation takes place whereby contact 158 moves against contact 164 and activates a battery of opposite polarity to operate the motor 118 in the reverse direction. This moves 35 the housing 42 up and moves the stylus in the recorder 104 in the opposite direction.

The threads on the shaft 48, the teeth on the gear 116 and the dimensions of the graph paper in the recorder are correlated with each other to accurately measure the 70 change in water level, which is also continuously indicated on the indicator 124.

If a stream or other body of water is in a locality which normally has water of a specific gravity different from 1.00, it is desirable to be able to compensate for this 75 difference without changing gear ratios or threads per 


\section{5}

inch on the shaft 68 . This is accomplished in the present invention by securing the supporting member 84 at an angle to the vertical. Since the shaft is thereby inclined while the housing $\mathbf{4 2}$ remains vertical because of its angular connection to the shaft 68 , the ratio of the number of turns of the shaft to the distance moved by the housing may be made variable. This is accomplished by changing the inclination of the supporting member 84 by means of the rocker 110 to correspond to the variation in specific gravity of the water.

Since the change of inclination of member 84 also changes the position of the housing 140 , this housing 140 is brought back to the vertical by pivoting it around bolt 192 until the level indicator 206 shows it in proper position. The angle of change of the inclination of the member 84 is then indicated by pointer 186 on scale 210 . The member 84 can be adjusted until the required density correction is indicated on the scale $\mathbf{2 1 0}$.

Although the desired action is obtained with the apparatus described above, the contact pressure available is much too light to maintain the current required by the motor. Furthermore, under natural stream conditions, a constant surging action takes place which would tend to keep the motor 118 almost constantly running in a humting manner. It is, therefore, necessary to use a relay circuit such as indicated in Fig. 9 which requires very little amperage in order to operate the motor 118 and to use a time delay circuit to eliminate the hunting action of the motor 118 due to surging of the water level. An electrical network to effect these desired operations is illustrated in Fig. 9.

The diagram in Fig. 9 shows the float 150 having the pivoted rod 152 between the contacts 164 and 166 . Contact 164 is connected through line 300 to battery 302, and contact 166 is connected through line 304 to battery 306 . The batteries are in circuit through normally closed switch 308 with both the coil 310 of relay 312 and with a potentiometer 314 through a resistance 316 . The potentiometer is connected through at selector switch 318 with a delay circuit including resistors $320,322,324$, and 326 of gradually increasing ohmic values. The resistor selected depends on the length of the surges encountered. The selected resistor, in conjunction with capacitor 328, applies a predetermined delayed impulse to glow tube 330 which is in circuit with one end of coil 332 of relay 334 . The opposite side of coil 332 is in circuit with contact rod 152 through line 336, switch 338 , which is normally closed, and line 340 .

The coil 332, when energized by glow tube 330, moves switch 342 against contacts 344 or 346 depending upon polarity of capacitor charge in the delay circuit. The switch 342 is connected through line 348 and line 350 to the coil 310 in relay $\mathbf{3 1 2}$, and, upon being moved against contacts 344 or 346 , establishes a circuit by shunting out the selected resistor in group 320 to 326 , from the delay relay 334 to the actuating relay 312 .

The coil 310, upon being energized, moves switch 352 against contacts 354 and 356 . This places one side of the motor 118 in circuit with the relay through switch 352 , line 358 and line 360 . At the same time, contact 356 is in circuit, through line 362 and line 364 , with the battery 366 for energizing the motor in one direction while contact 354 is in circuit, through lines 368 and 370 , with opposite battery 372 . If the circuit is from contact 166 through battery 306, the current is through battery 366 . However, with rod 152 in engagement with contact 164, the circuit is through battery 302 and battery 372 energizes the motor.

If the housing 42 is desired to be moved independently of the servo system shown in Fig. 9, the switch 374 is closed, which action simultaneously opens switch 308 and the switch 376 is moved against either contact 378 or 380 to close the independent circuit to the motor either through battery 366 or battery 372 depending on contact 378 or 380 being engaged.

\section{6}

Although this invention has been described in considerable detail, such description is intended as being illustrative rather than limiting, since the invention may be variously embodied, and the scope of the invention is to be determined as claimed.

Having thus set forth and disclosed the nature of this irvention, what is claimed is:

1. The system of claim 11 wherein said electrical network includes said electrical switch which has a movable

10 contact adapted to alternately engage either of a pair of fixed contacts, one of said fixed contacts being in circuit with a first battery of one polarity and the other of said fixed contacts being in circuit with a second battery of opposite polarity, both of said batteries being in circuit 15 with the coil of a first relay and with the coil of a second relay, said second relay including a resistance-capacitor circuit wherein the resistor is selectively variable, and also including a glow tube, said glow tube being fired upon a predetermined voltage being applied across the 20 resistor-capacitor circuit, said second relay being in circuit with the coil of said first relay to energize said first relay upon firing of said glow tube, and said first relay being in circuit with the motor through individually activated motor actuating batteries of opposite polarity.

2. The network of claim 1 wherein a normally closed switch is provided to open the circuit between the contacts and the motor actuating batteries.

3. The network of claim 2 wherein a normally open switch means is provided to form a closed circuit be30 tween said motor-actuating batteries and said motor when said normally closed switch is open.

4. The network of claim 1 wherein said resistor-capacitor circuit includes a plurality of resistors of different ohmic values, and a selector switch selectively placing 35 each of said resistors individually in the circuit.

5. In a fluid condition indicating system, a pressare responsive member adapted to be extended into a body of fluid, means for introducing gas under pressure into said pressure responsive member, a base, a support angularly 10 disposed on said base, a first housing, means mounting said first housing on said support, a first manometer liquid pool in said first housing, a fluid connection between said pressure responsive member and said first housing, a second housing, means mounting said second housing on said support, a second manometer liquid pool in said second housing, a conduit connecting said first and second housings, a column of manometer liquid in said conduit, a linear track on said support, means carried by said first housing engaging said track for movement of said first housing therealong, a screw shaft threadedly engaged by said first housing, reversible motor means mounted on said support for rotating said screw to move said first housing, an electrical switch associated with said second housing, actuable by variations in the level of said second manometer liquid pool to actuate said motor means in either direction, the level of said manometer liquid pool being determined by pressure of gas in said first housing, and the pressure of said gas being determined by the condition of the fluid being indicated relative to said pressure responsive member, an indicating means, gearing operatively connecting said indicating means to said motor for simultaneous actuation with said shaft, and means for varying the angular inclination of said support relative to said base to compensate for variations'proportioned to pressure in a condition of said fluid other than the condition indicated, by varying the mean vertical movement of said first-mentioned housing and its associated manometer liquid pool without varying the actual linear movement thereof.

6. In a fluid condition indicatiog system, a pressure responsive member adapted to be extended into a body of fluid, means for introducing gas under pressure into said pressure responsive member, a base, a support angularly disposed on said base, a flrst housing, means 75 mounting said first housing on said support, a first ma- 
nometer liquid pool in said first housing, a fluid connection between said pressure responsive member and said first housing, a second housing, means mounting said second housing on said support, a second manometer liquid pool in said second housing, a conduit connecting said first and second housings, a column of manometer liquid in said conduit, a linear track on said support, means carried by said first housing engaging said track for movement of said first housing therealong, a screw shaft threadedly engaged by said first housing, reversible motor means mounted on said support for rotating said screw to move said first housing, an electrical switch associated with said second housing, actuable by variations in the level of said second manometer liquid pool to actuate said motor means in either direction, the level of said manometer liquid pool being determined by pressure of gas in said first housing, and the pressure of said gas being determined by the condition of the fluid being indicated relative to said pressure responsive member, an indicating means, gearing operatively connecting said indicating means to said motor for simultaneous actuation with said shaft, means for varying the angular inclination of said support relative to said base to compensate for variations proportioned to pressure in a condition of said fluid other than the condition indicated, by varying the mean vertical movement of said first-mentioned housing and its associated manometer liquid pool without varying the actual linear movement thereof, means to vary the angular inclination of said first housing relative to said support to maintain said first manometer liquid pool level regardless of the angle of inclination of said support, and means to vary the angle of said second housing relative to said base for corresponding leveling of said second manometer liquid pool.

7. In a fluid condition indicating system, a pressure responsive member adapted to be extended into a body of fluid, means for introducing gas under pressure into said pressure responsive member, a base, a support angularly disposed on said base, a first housing, means mounting said first housing on said support, a first manometer liquid pool in said first housing, a fluid connection between said pressure responsive member and said first housing, a second housing, means mounting said second bousing on said support, a second manometer liquid pool in said second housing, a conduit connecting said first and second housings, a column of manometer liquid in said conduit, a linear track on said support, means carried by said first housing engaging said track for movement of said first housing therealong, a screw shaft threadedly engaged by said first housing, reversible motor means mounted on said support for rotating said screw to move said first housing, an electrical switch associated with said second housing, actuable by variations in the level of said second manometer liquid pool to actuate said motor means in either direction, the level of said manometer liquid pool being determined by pressure of gas in said first housing, and the pressure of said gas being determined by the condition of the fluid beieg indicated relative to said pressure responsive member, an indicaing means, gearing operatively connscting said indicating means to said motor for simulianeous actuation with said shaft, means for varying the angular inclination of said support relative to said base to compensate for variations proportioned to pressure in a condition of said fluid other than the condition indicated, by varying the mean vertical movement of said first-mentioned housing and its associated manometer liquid pool without varying the actual linear movement thereof, means to vary the angular inclination of said first housing relative to said support to maintain said first manometer liquid pool in level position regardless of the angle of inclination of said support, means to vary the angle of said second housing relative to said base for corresponding leveling of said second manometer liquid pool, and means for securing said support, said first housing, and said second housing in angularly adjusted position.

8. In a liquid level measuring and recording motored manometer system, a pressure responsive tube adapted to - be extended into a body of liquid, means for introducing gas under pressure into said tube, a base, a support angularly disposed on said base, a first housing, means pivotally mounting said first housing on said support, a mercury pool in said first housing, a fluid connection between

10 said tube and said first housing, a second housing, means pivotally mounting said second housing on said support, a second manometer liquid in said second housing, a conduit connecting said first and second housings, a column of mercury in said conduit, a linear track on said sup-

18 port, means carried by said first bousing engaging said track for movement of said first housing therealong, a screw shaft extending parallel to said track threadedly engaged by said first housing, reversible motor means fixedly mounted on said support for rotating said screw 20 to move said first housing linearly along said track, an electrical switch associated with said second housing actuable by variations in the level of said second mercury pool to actuate said motor means in either direction, the level of said second mercury pool being determined by

25 pressure of gas in said first housing and the pressure of said gas being determined by the level of the liquid being measured relative to said tube, a recording means, gearing operatively connecting said recording means to said motor for simultaneous actuation with said shaft, and 30 means for varying the angular inclination of said support relative to said base and hence the angular inclination of said track to compensate for variations in specific gravity in said fluid by varying the mean vertical movement of said first-mentioned housing and its associated mercury 35 pool without varying the actual linear distance traveled along said track.

9. In a liquid level measuring and recording motored manomter system, a pressure responsive tube adapted to be extended into a body of liquid, means for introducing

10 gas under pressure into said tube, a base, a support angularly disposed on said basc, a first housing, means pivotally mounting said first housing on said support, a mercury pool in said first bousing, a fluid connection between said tube and said first housing, a second housing, 45 means pivotally mounting said second housing on said support, a second manometer liquid in said second honsing, a conduit connecting said first and second housings, a column of mercury in said conduit, a linear track on said support, means carried by said first housing engag-

50 ing said track for movement of said first housing therealong, a screw shaft extending parallel to said track threadedly engaged by said first housing, reversible motor means fixedly mounted on said support for rotating said screw to move said first housing linearly along said track,

55 an electrical switch associated with said second bousing actuable by variations in the level of said second mercury pool to actuate said motor means in either direction, the level of said second mercury pool being determined by pressure of gas in said first housing and the pressure of 60 sdid gas being determined by the level of the liquid being measured relative to said tube, a recording means, gearing operatively connecting said recording means to said motor for simultaneous actuation with said shaft, means for varying the angular inclination of said support rela06 tive to said base and hence the angular inclination of said track to compensate for variations in specific gravity in said fluid by varying the mean vertical movement of said first-mentioned housing and its associated mercury pool without varying the actual linear distance travelled along said track. means to vary the angular inclination of both said first housing and said second housing relative to said support to level said first and second mercury pools regardless of the angular inclination of anid supo 
Ing and said second housing in angularly adjusted position.

10. In a liquid level measuring and recording motored manometer system, a pressure responsive tube adapted to be extended into a body of liquid, means for introducing gas under pressure into said tube, a base, a support angularly disposed on said base, a first housing, means pivotally mounting said first housing on said support, a mercury pool in said first housing, a fluid connection between said tube and said first housing, a second housing, means pivotally mounting said second housing on said support, a second manometer liquid in said second housing, a conduit connecting said first and second housings, a column of mercury in said conduit, a linear track on said support, means comprising a first plate having rollers along one edge thereof, a second plate of bellcrank configuration pivotally connected to said first plate, a roller on the short leg of said second plate, and a resilient connection between the other leg of said second plate and said first plate, carried by said first housing engaging said track for movement of said first housing therealong, a screw shaft extending parallel to said track, a bracket having a threaded aperture therein carried by said first housing, said threaded aperture engaged by said screw shaft, reversible motor means fixedly mounted on said support for rotating said screw to move said first housing linearly along said track, an electrical switch associated with said second housing actuable by variations in the level of said second mercury pool to actuate said motor means in either direction, the level of said second mereury pool being determined by pressure of gas in said first bousing and the pressure of said gas being determined by the level of the liquid being measured relative to said tube, a recording means, gearing operatively connecting said recording means to said motor for simultaneous actuation with said shaft, and means for varying the angular inclination of said support relative to said base and hence the angular inclination of said track to compensate for variations in specific gravity in said fluid by varying the mean vertical movement of said first-mentioned housing and its associated mercury pool without varying the actual linear distance travelled along said track.

11. In a liquid level measuring and recording motored manometer system, a pressure responsive tube adapted to be extended into a body of liquid, means for introducing gas under pressure into said tube, a base, a support angularly disposed on said base, a first housing, means pivotally mounting said first housing on said support, a mercury pool in said first housing, a fluid connection between said tube and said first housing, a second housing, means pivotally mounting said second housing on said support, a second manometer liquid in said second housing, a conduit connecting said first and second housings, a column of mercury in said conduit, a linear track on said support, means carried by said first housing engaging said track for movement of said first housing therealong, a screw shaft extending parallel to said track, threadedly engaged by said first housing, reversible motor means fixedly mounted on said support for rotating said screw to move said first housing linearly along said track, an electrical switch associated with said second housing actuable by variations in the level of said second mercury pool to actuate said motor means in either direction, an electrical network including a time delay circuit connected between said electrical switch and said motor means to eliminate hunting action of the motor means due to surging of the water level, the level of said second mercury pool being determined by pressure of gas in said first housing and the pressure of said gas being determined by the level of the liquid being measured relative to said tube, a recording means, gearing operatively connecting said recording means to said motor for simultaneous actuation with said shaft, and means for varying the angular inclination of said support relative to said base and hence the angular inclination of said track to compensate for variations in
10

specific gravity in said fluid by varying the mean vertical movement of said first-mentioned housing and its associated mercury pool without varying the actual linear distance travelled along said track.

12. In a liquid level measuring and recording motored manometer system, a pressure responsive tube adapted to be extended into a body of liquid, means for introducing gas under pressure into said tube, a base, a support angularly disposed on said base, a first housing, means

10 pivotally mounting said first housing on said support, a mercury pool in said first housing, a fluid connection between said tube and said first housing, a second housing means pivotally mounting said second housing on said support, a second manometer liquid in said second hous16 ing, a conduit connecting said first and second housings, a column of mercury in said conduit, a linear track on said support, means carried by said first housing engaging said track for movement of said first housing therealong, a screw shaft extending parallel to said track threadedly 20 engaged by said first housing, reversible motor means fixedly mounted on said support for rotating said screw to move said first housing linearly along said track, an electrical switch associated with said second housing actuable by variations in the level of said second mereury pool to actuate said motor means in either direction, the level of said second mercury pool being determined by pressure of gas in said first housing and the pressure of said gas being determined by the level of the liquid being measured relative to said tube, a recording means, gearing

30 operatively connecting said recording means to said motor for simultaneous actuation with said shaft, means for varying the angular inclination of said support relative to said base and hence the angular inclination of said track to compensate for variations in specific gravity in 35 said fluid by varying the mean vertical movement of said first-mentioned housing and its associated mercury pool without varying the actual linear distance travelled along said track, and a numerical indicator mechanism operatively connected to said gearing for indicating the liquid 40 level at any existing moment.

13. In a liquid level measuring and recording motored manometer system, a pressure responsive tube adapted to be extended into a body of liquid, means for introducing gas under pressure into said tube, a base, a support 55 angularly disposed on said base, a first housing, means pivotally mounting said first housing on said support, a mercury pool in said first housing, a fluid connection between said tube and said first housing, a second housing, means pivotally mounting said second housing on said

so support, a second manometer liquid in said second housing, a conduit connecting said first and second housings, a column of mereury in said conduit, a linear track on said support, means carried by said first housing engaging said track for movement of said first housing there-

56 along, a screw shaft extending parallel to said track, threadedly engaged by said first housing, reversible motor means fixedly mounted on said support for rotating said screw to move said first housing linearly along said track, an electrical switch associated with said second housing 60 actuable by variations in the level of said second mercury pool to actuate said motor means in either direction, the level of said second mercury pool being determined by pressure of gas in said first housing and the pressure of said gas being determined by the level of the Liquid being measured relative to said tube, a graphic recording instrument for continuously recording the liquid level against time, gearing operatively connecting said graphic recording instrument to said motor for simultaneous actuation of said shaft, means including a rocker on said support and a pivoted connection between said rocker and said base for varying the angular inclination of said support relative to said base and hence the angular inclination of said track to compensate for variations in specific gravity in said fluid by varying the mean vertical movement of said first-mentioned housing and its 
11

associated mercury pool without varying the actual linear distance travelled along said track, and a numerical indicator mechanism operatively connected to said gearing for indicating the liquid level at any existing moment.

14. Apparatus for indicating a condition in a body of liquid comprising a container for a column of pressured gas adapted to be immersed into said body of liquid, means adjusting the pressure of the gas to balance the pressure of the liquid level, a housing containing a first pool of manometer liquid, a second bousing containing a second pool of manometer liquid in fluid communication with said first bousing, means applying the pressure of said column of gas against said first pool whereby change in the level of the liquid being measured varies the level of the manometer liquid in the second pool, a drive means, means actuable by variations in the level of the second pool to actuate said drive means, a connection between said drive means and said first housing for varying the vertical position of the first pool relative to the second pool until a balance is achieved, means for vary- 20 ing the vertical distance travelled by the first pool toward the balance position without varying the absolute distance travelled whereby to compensate for conditions in the body of liquid proportionate to pressure other than the condition being indicated, and a device for indicating the 2 change of absolute distance travelled by the first pool.

15. Apparatus for measuring and recording variations in the level of a body of liquid comprising a container for a column of pressured gas adapted to be immersed into said body of liquid, means adjusting the pressure of 30 the gas to balance the pressure of the liquid level, a housing containing a first pool of manometer liquid, a second

\section{2}

housing containing a second pool of manometer liquid in fluid communication with said first housing, means applying the pressure of said column of gas against said first pool whereby change in the level of the liquid being 5 measured varies the level of the manometer liquid in the in the level of the second pool to actuate said drive means, a connection between said drive means and said first housing for varying the vertical position of the first

10 pool relative to the second pool until a balance is achieved, means for varying the vertical distance travelled by the first pool toward the balance position without varying the absolute distance travelled thereby to compensate for conditions in the body of liquid proportionate to pres-

16 sure other than liquid level, and a graphic recorder for continuously recording the change of absolute distance travelled by the first pool against time.

\section{References Clted in the file of this patent UNITED STATES PATENTS}

$1,261,262$
$1,699,812$

$1,699,812$
$2,266,955$

$2,380,177$

$2,389,508$

$2,441,149$

$2,502,167$

$2,609.687$ 30

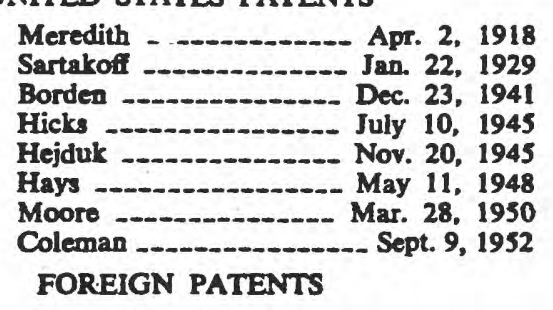

886,024
France

June 15, 1943 


\section{Appendix VII--Formation and Continuation of the Instrument Development Laboratory \\ Columbus, Ohio \\ By $\mathrm{Hal}$ wires \\ (Written Communication, 1975)}


FORMATION AND CONTINUATION OF THE INSTRUMENT DEVELOPMENT LABORATORY COLUMBUS, OHIO

By Hal Wires

In 1ate 1953, as a result of influence by Joe Wells, then Surface Water Branch Chief of USGS, Hal Wires transferred from a field project at Lake Meade, Nevada, to Columbus for the purpose of joining Ed Barron at a later date to establish an instrument development effort specially focused on Surface Water Branch problems. Consultation and assistance was extended by Larry Crawford, Columbus District Engineer, and Art Frazier, Chief of the Equipment Development Laboratory in who's [sic] warehouse this new facility was quartered at $858 \mathrm{King}$ Avenue.

Early in 1954, Ed Barron officially transferred from the Kentucky District office to assume the duties of Engineer-in-Charge of this laboratory unit. In early 1956, George Smoot transferred from Palmer, Alaska, to join Barron and Wires. Except for part time help and some relatively short-term employees, these three were the staff until 1959 when the Equipment Development Laboratory (EDL) was disbanded. At that time Harold Cox of the extinct EDL joined the staff and the headquarters moved to 1509 Hess Street, the space previously occupied by the EDL.

Clerical and administrative positions were in cooperation with EDL and Columbus District staff. The people holding these positions were as follows:

\author{
Katherine Eisel, Clerk Typist; \\ Margaret Jordan, Clerk Typist; \\ Harriett Vance, Clerk Typist; \\ Donna Belt, Administrative Clerk; and \\ John Rowse, Administrative Assistant.
}

The following describes other personnel changes except for students or short-term employees:

August 1959, hired Sam Rickly WAE Mechanical Engineer (Assistant Professor at OSU);

October 1959, hired Don Cahal (Physicist), transferred to Washington, D.C., September 1961;

January 1960, hired Jerry Mayles (Engineer Aid), resigned June 1965;

January 1962, Thomas Kollar (Technician) transferred in from WRD Pittsburgh, $\mathrm{Pa}$.;

July 1962, George Smoot transferred to Washington, D.C. ;

December 1964, Edgar Barron retired, and Hal Wires assumed duties of Engineer-in-Charge;

July 1965, Sam Rickly (Mechanical Engineer) joined staff full time;

June 1965, Duane Preble (Electronic Engineer) Joined staff;

During July of 1967, the Instrument Development Laboratory quarters were moved to 975 West Third Avenue, to occupy adjoining space with the reorganized Ohio District offices of the Water Resources Division with John J. Malloy as District Chief; 
November 1968, Harold Cox retired with 40 years service; and August 1969, Ray Lafferty (Technician) transferred in from Phoenix, AZ.

In January of 1971, following a proposal by NASA to the USGS, and other agencies, Wires and Rickly visited the Mississippi Test Facility of the George C. Marshall Space Flight Center at Huntsville, Alabama. Located in Bay St. Louis, Mississippi, the offer included construction of Hydraulic test facilities and modification to building 2101 for general offices and space for the Instrument Development Laboratory. A floor plan and general details for the modification of 2101 were worked out at that time.

Following Congressional approval in late May of 1-1/2 million dollar expenditure by NASA for the USGS facilities, final organizational planning was accomplished at WRD Washington headquarters. Therefore, in June and July of 1971, the equipment and office of the Instrument Development Laboratory were packed for shipment to MTF, Bay St. Louis, Mississippi.

To reorganize the Instrument Development Laboratory in August 1971, the following personnel, and the offices from which they transferred, are 1isted:

Hal Wires, Columbus, Ohio;

Samuel E. Rickly, Columbus, Ohio;

Duane M. Preble, Columbus, Ohio;

Thomas Kollar, Columbus, Ohio;

Ray Lafferty, Columbus, Ohio;

James Ficken, Washington, D.C. ;

A.E. Robinson, Washington, D.C.; and

Wayne George, Washington, D.C.

Administrative functions were performed through the Columbus, Ohio, WRD District office until January 1972, when Selvia Kennedy joined the staff and assumed these duties. Wayne George resigned in 1972. Billie McDonald transferred from Rolla, Missouri, in May 1972, and assumed responsibilities for meter rating and repair, and for the bathymetric survey.

As the electronic design problems increased, James Rorabaugh joined the laboratory as a new electrical engineering graduate from Rolla School of Mines in June 1973. Additional technical support was supplied by William Rapp, who reported to work in December 1973.

Tom Kollar transferred to Louisville, Kentucky, in April 1974, and was replaced by Gary Loman who transferred from Ithaca, New York, in May.

In late 1974, a satellite data collection receive site was implemented to be a project function under Duane Preble. On-site General Electric contract personnel were mainly responsible for man-hours in setting up this site, but Nancee Dinkel, James Capezza and Charles Anderson were added to the staff as USGS support necessary for logistics, software and interfacing hardware. Therefore, in 1975, the staff for the Instrument Development Laboratory was: 
H.O. Wires, Electrical Engineer;

S.E. Rickly, Mechanical Engineer;

J.H. Ficken, Chemical Engineer;

B.L. McDonald, Hydrologic Engineer;

A.E. Robinson, Hydrologic Technician;

R. Lafferty, Electrical Engineer;

J.I. Rorabaugh, Electrical Engineer;

G.E. Loman, Hydrologic Techniclan;

W.L. Rapp, Electrical Technician; and

S.A. Kennedy, Administrative Clerk.

Personnel for the Satellite Data Relay Support Project included the following:

D.M. Preble, Electrical Engineer;

J.R. Capezza, Mathematician;

C.E. Anderson, Electrical Technician; and

N.D. Dinke1, Clerk, Typist. 